\title{
Correlação entre gestão da tecnologia e gestão ambiental nas empresas
}

\author{
José Carlos Teixeira da Silva \\ Eng. de Produção / FEB - UNESP \\ Marcos Schaaf Teixeira da Silva \\ Saneamento e Controle Ambiental / UNICAMP \\ Jair Wagner de Souza Manfrinato \\ Eng. de Produção / FEB - UNESP
}

\begin{abstract}
Resumo
Este trabalho analisa a correlação entre a gestão da tecnologia de produtos e processos e a gestão ambiental em empresas de manufatura. Partindo de um modelo conceitual simplificado e desdobramentos das dimensões gestão da tecnologia e gestão ambiental, foi possível analisar em pesquisa de campo vários conceitos disponíveis na literatura para esses dois campos, envolvendo 78 empresas do setor de manufaturados, através de "projeto de pesquisa survey" e "projeto de pesquisa qualitativa". Visando avaliar a capabilidade tecnológica das organizações, foram usados os conceitos de microtecnologia e macrotecnologia relatados em Silva (2003). Concluiu-se que, dentro do campo pesquisado de empresas, existe correlação positiva entre os níveis de capabilidade tecnológica e os níveis de capabilidade ambiental.
\end{abstract}

\section{Palavras-chave}

Tecnologia, gestão da tecnologia, gestão ambiental.

\section{Correlation between technology management and environmental management in the companies}

\begin{abstract}
This work analyzes the correlation between the technology management of products and processes and the environmental management, in manufacture companies. Leaving from a simplified conceptual model, and doing deployment of the dimensions technology management and environmental management, it was possible to analyze several concepts available in the literature for these fields, involving 78 manufacture companies, through "survey research project" and "qualitative research project", regarding also the technology capability of the organization through the new concepts of microtecnologia and macrotecnologia related in Silva (2003). It concluded that, inside the field searched of companies, there is a positive correlation between the levels of technology capability and environmental capability.
\end{abstract}

\section{Key words}

Technology, technology management, environmental management. 


\section{INTRODUC̣ÃO E OBJETIVOS}

O termo "gestão da tecnologia" teve origem na segunda metade da década de 1980 nos Estados Unidos da América - EUA, envolvendo governo, empresas e universidades, visando o desenvolvimento, estudo e pesquisas de aspectos relacionados às tecnologias de produto e processo das organizações, dentro da abordagem da teoria organizacional das empresas. Desde a década de 1990 muitos trabalhos têm sido desenvolvidos nesse campo com o apoio da National Science Foundation-NSF, através de universidades americanas como Harvard, MIT, Stanford, e University of Cambridge na Inglaterra, com programas conjuntos de pesquisa nesse campo. Esse direcionamento ocorreu depois da equalização dos níveis de qualidade entre as empresas americanas e japonesas, no contexto das "empresas de classe mundial" segundo a caracterização de Merli (1994), destacando-se a tecnologia como uma nova dimensão de competitividade no contexto do mercado globalizado. Dentro dessa nova abordagem, Dodgson (2000) discute alguns conceitos de gestão da tecnologia, de gestão da inovação e de inovação tecnológica, onde argumenta que "a inovação tecnológica é uma atividade de importância crítica, que se tornou estratégia principal para a competição no século 21". A partir do ano 2000 constata-se a segmentação de conceitos da gestão da tecnologia para alguns setores da economia, como equipamentos médicos, equipamentos de telefonia e comunicação etc., embora seja ainda tímida essa movimentação. Somente com essa segmentação será possível implementar ganhos consideráveis nos diferentes setores da economia, com tecnologias competitivas direcionadas para produtos e processos específicos de um setor industrial. Essa abordagem diversifica e segmenta o conhecimento existente para o uso de diferentes tecnologias nos diferentes setores, além da geração de novas tecnologias. O setor de "bens de capital" merece toda atenção porque é o fornecedor de equipamentos para o processo de produção de indústrias de vários setores da economia. O conteúdo e valor agregado, das tecnologias embutidas nos "bens de capital", são fatores importantes para os processos produtivos, influenciando a produtividade, e em alguns casos a competitividade de curto prazo, pois esses equipamentos estão disponíveis no mercado.

Nos últimos anos temos desenvolvido vários estudos e trabalhos de pesquisa no campo da gestão da tecnologia, envolvendo empresas do setor de manufaturados, como pode ser constatado em Silva; Plonski (1996), Silva (1999a), Silva (1999b), Silva (2001), Silva (2002a), Silva (2002b), e Silva (2003). Nesse contexto foram abordados vários aspectos das tecnologias de produto e processo, incluindo as implicações da existência ou não de desenvolvimento dessas tecnologias no âmbito das organizações, influenciando dessa forma o campo de desenvolvimento de produtos e processos, como final de um modelo não-linear que poderá conduzir ou não para inovações tecnológicas. Uma das conclusões importantes, decorrente da continuidade da pesquisa, constante em Silva (2003), foi o desenvolvimento de novos conceitos e dimensões da palavra "tecnologia", incluindo a "microtecnologia" para produtos e processos, e a "macrotecnologia" para a organização como um todo. Enquanto que essa última envolve o contexto da "formulação e gestão do conhecimento das tecnologias", a primeira está relacionada à operacionalização desse conhecimento em produtos e processos como resultado final para o mercado.

Essa nova abordagem do conceito de "tecnologia" permite uma avaliação com maior detalhamento da capacitação tecnológica de uma organização, devido ao desdobramento da microtecnologia em "tecnologia principal" e "tecnologias complementares", aplicáveis tanto para os produtos como para os processos de produção, como se pode constatar em Silva (2003). Desta forma podemos visualizar o potencial de competitividade de uma organização, no contexto tecnológico, em um momento histórico de um determinado mercado. Por outro lado, esse desdobramento também permite analisar, com maior precisão, os aspectos de meio ambiente decorrentes das atividades da empresa, incluindo também as necessidades e uso de energia. Qualquer alteração no contexto tecnológico de uma organização influencia o meio ambiente interno e externo à organização, como assinala Wolstenholme (2003). Como conseqüência dessa alteração temos reflexos diretos no desenvolvimento de produtos, de acordo com Hillebrand; Biemans (2004), onde a cooperação interna e externa é essencial. Também nesse contexto a medição da produtividade em P\&D implica em diferenciar "pesquisa" de "desenvolvimento", como assinalaram corretamente Karlsson et al. (2004) na busca de parâmetros de medição de um "output da empresa", aí incluídos os produtos, os processos, os sistemas, o meio ambiente e todas as relações com a comunidade. Embora não seja possível programar uma inovação tecnológica, é possível por outro lado criar meios de absorção e desenvolvimento de novos conhecimentos dentro da organização, tendo noção da real diferenciação entre a pesquisa e o desenvolvimento, bem como dos reflexos da alteração de uma tecnologia dentro e fora da empresa. Somente a capabilidade (capacidade + habilidade) tecnológica de uma organização induz ao trabalho constante de desenvolvimento das tecnologias principais dos produtos e processos dentro de seu segmento de mercado. 
Na conceituação de "resíduos" ("waste") estabelecida em White et al. (1996) podemos distinguir um ciclo onde poderá ou não haver reciclagem dos materiais, ou seja, materiais que podem recuperar ou não seu valor econômico. Esse aspecto depende das tecnologias utilizadas no processo produtivo e das características dos resíduos, ou seja, estado físico, uso original, tipo de material, propriedades físicas, origem, nível de segurança etc. Quando de resíduos sólidos, a reciclagem, se existente, poderá ser conduzida para o mesmo processo gerador ou para processos alternativos. No caso de resíduos líquidos ou gasosos essa reciclagem é mais trabalhosa e geralmente inviável economicamente, fazendo com que as empresas se preocupem no máximo em atender a legislação ambiental. Por outro lado, também devemos analisar sob o ponto de vista do produto, ou seja, se sua utilização implica em geração de resíduos e o que ocorre no final de seu ciclo de vida útil.

O presente trabalho analisa os principais aspectos da gestão da tecnologia em empresas, utilizando novos conceitos de "tecnologia" desenvolvidos anteriormente, de acordo com Silva (2003), procurando correlacionar e discutir sua influência quanto a aspectos de meio ambiente. Essa abordagem, envolvendo tanto conceitos da gestão da tecnologia, como pesquisa de campo, está relacionada às tecnologias de produto/processo (microtecnologia), capabilidade tecnológica da organização (macrotecnologia), aspectos estratégicos e operacionais das tecnologias utilizadas pela organização. Com relação à pesquisa de campo, envolve "survey" e entrevistas em pequenas e médias empresas tradicionais do setor de manufaturados, visando detectar o nível de co- nhecimento dessas organizações nesse campo. Esses dados, juntamente com os resultados de outras pesquisas nesse campo, são relevantes para proposições futuras de otimização dentro do campo da teoria organizacional das empresas, correlacionando a gestão da tecnologia com a gestão ambiental.

\section{CONCEITUACÃO E METODOLOGIA}

\section{Conceituação}

A conceituação envolvida neste trabalho engloba duas dimensões importantes para as empresas de manufatura, como a gestão da tecnologia e a gestão ambiental, simbolicamente representadas através do modelo conceitual simplificado da Figura 1, as quais serão posteriormente desdobradas em seus vários aspectos.

Dentro da gestão da tecnologia podemos incorporar os conceitos de microtecnologia de produtos e processos, de acordo com a Figura 2. Além do desdobramento da microtecnologia em tecnologias principais e complementares, serão considerados aspectos estratégicos e operacionais relacionados às tecnologias, desenvolvimento de produtos e processos, bem como sua inserção no planejamento estratégico da empresa, de acordo com Silva (2002b). Nesse campo, Swan; Allred (2003) indicam que "a questão crucial se concentra nas vantagens e desvantagens do desenvolvimento ou compra de tecnologia". A nosso ver o desenvolvimento é sempre vantajoso, pois na realidade não se pode "comprar conhecimentos de uma tecnologia", e sim no máximo "informação", que por si só não gera conhecimento, como assinalamos em Silva (2003). O termo "transferência de tecnologia" é

Figura 1: Modelo conceitual simplificado.

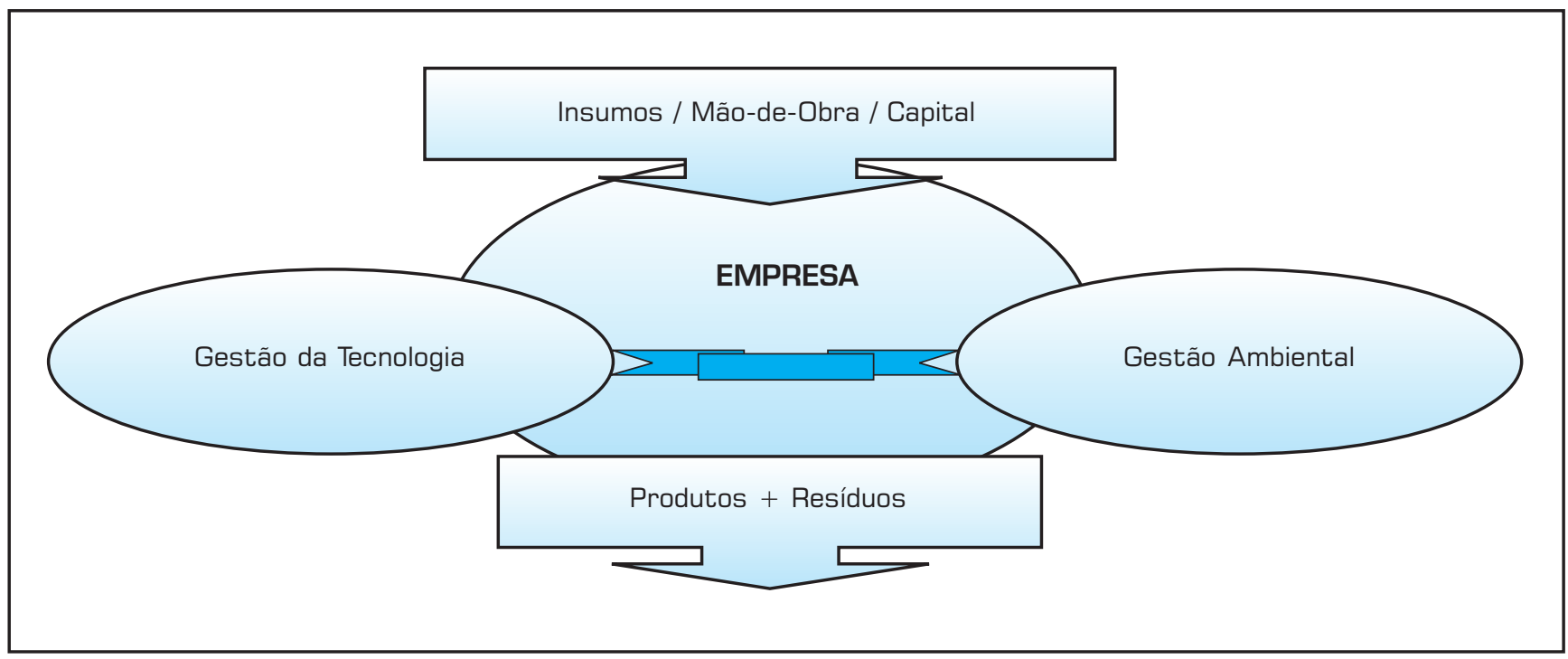


muito discutível e impraticável no contexto dos conceitos de macro e microtecnologias. Quando ocorre o "licenciamento de uma tecnologia", nada garante a transferência para o receptor de todo o conhecimento embutido.

Com relação à microtecnologia do produto, tanto a tecnologia principal como as tecnologias complementares poderão influenciar os aspectos de meio ambiente. Após a vida útil do produto resta então seu descarte ou reutilização como matéria-prima para outros processos industriais. No campo da microtecnologia de processo, as tecnologias principais e complementares, em cada fase do processo de produção, influenciam diretamente a geração de resíduos e efluentes, sendo assim fundamentais dentro da gestão ambiental da empresa.

Evidentemente as microtecnologias de produto e processo são resultados da macrotecnologia da organização e do planejamento estratégico das tecnologias, dos produtos, e da empresa de maneira global. Nesse campo podemos destacar o enfoque central dado por Michael et al. (2000) quando analisaram "a importância do desenvolvimento do aprendizado tecnológico e da gestão do conhecimento para a competitividade, crescimento, e sobrevivência da organização", bem como os trabalhos de Mohrman et al. (2003) quando procuraram conhecer o sistema de geração de conhecimentos em uma empresa visando o desenvolvimento de produtos.

A Figura 3 apresenta um esquema das empresas tradi- cionais que operam no "modelo linear clássico" dentro do contexto de meio ambiente, ou seja, contenção e tratamento, quando existentes, somente após a geração dos resíduos.

Mais recentemente, a questão ambiental tem levado as empresas modernas a se preocuparem com a não geração de resíduos, ou minimização e prevenção, incorporando o uso de conceitos relacionados à "produção limpa" e "produção mais limpa". No campo de estratégias de gestão ambiental e os negócios da empresa, Furtado et al. (2001) analisaram em profundidade a evolução das políticas de meio ambiente no meio empresarial considerando vários aspectos e conceitos importantes nesse campo. A Figura 4 apresenta, por outro lado, um esquema de "modelo industrial não-linear" no contexto da gestão ambiental, onde se tem uma visão global do sistema e suas correlações no que se refere à prevenção e reciclagem de resíduos. Nesse campo Petersen et al. (2003) destacaram a importância da integração com fornecedores, para desenvolver novos produtos, desde o início desse processo.

É interessante ressaltar que na atualidade está se repetindo com a gestão ambiental o mesmo que ocorreu nas décadas de 1980/90 com a gestão da qualidade e a ISO 9000, ou seja, "a implantação de um sistema administrativo de gestão ambiental, mesmo com a certificação da ISO 14000, não garante compromissos em relação a

Figura 2: Microtecnologia: conjunto de tecnologias de produto/processo - Silva(2003).

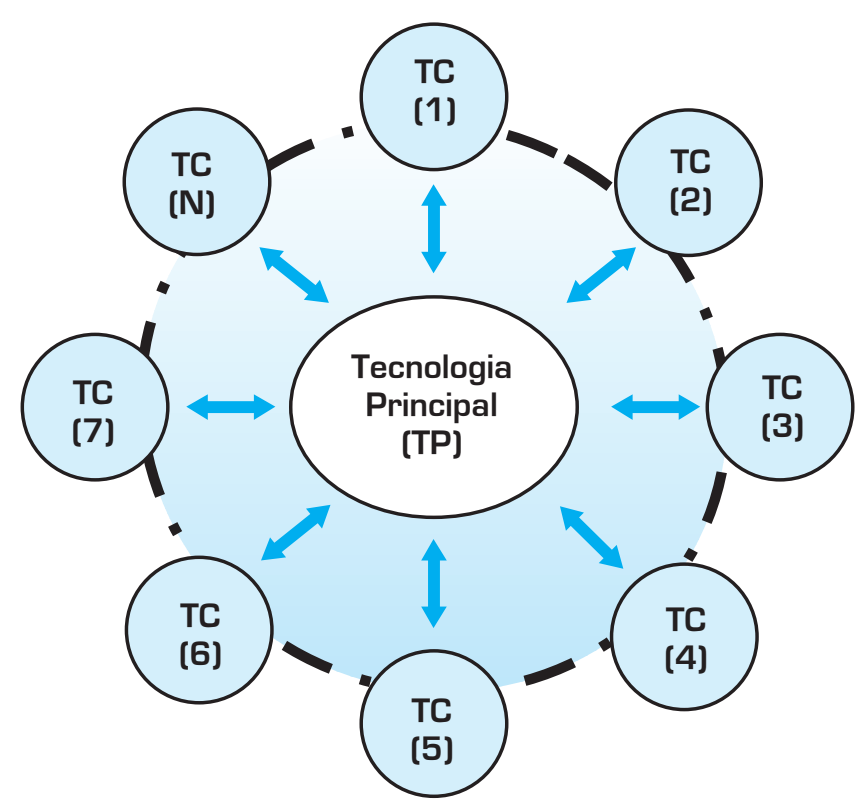


eco-eficiência". Vários fatores de ordem política e estratégica, de capabilidade tecnológica, de informação, de comunicação e de legislação devem ser considerados no processo de tomada de decisões para operação em "modelo não-linear", incluindo incorporação de conceitos de "produção limpa" e de "produção mais limpa". De acordo com Furtado (1998) "as indústrias já dispõem de meios para reorientar o sistema de produção de bens e serviços, com o emprego de produção mais limpa, produção limpa, ecodesign e outros instrumentos ambien- talmente adequados. Para isso, será necessário conscientização e requalificação do pessoal, evitando o uso equivocado dos termos verde, eco, ecologia ou da expressão desenvolvimento sustentável, causado pelo despreparo dos agentes ou pela deliberada maquiagem verde (greenwashing)". Ainda segundo Furtado (1998) e Furtado et al. (2001) "as empresas, usualmente, vêem o Sistema de Gestão Ambiental - correlacionado, em geral, com a ISO 14001 - como estratégia importante para aprimorar seu desempenho, inclusive em relação à ex-

Figura 3: Modelo industrial linear clássico - Furtado et al. [2001\}.

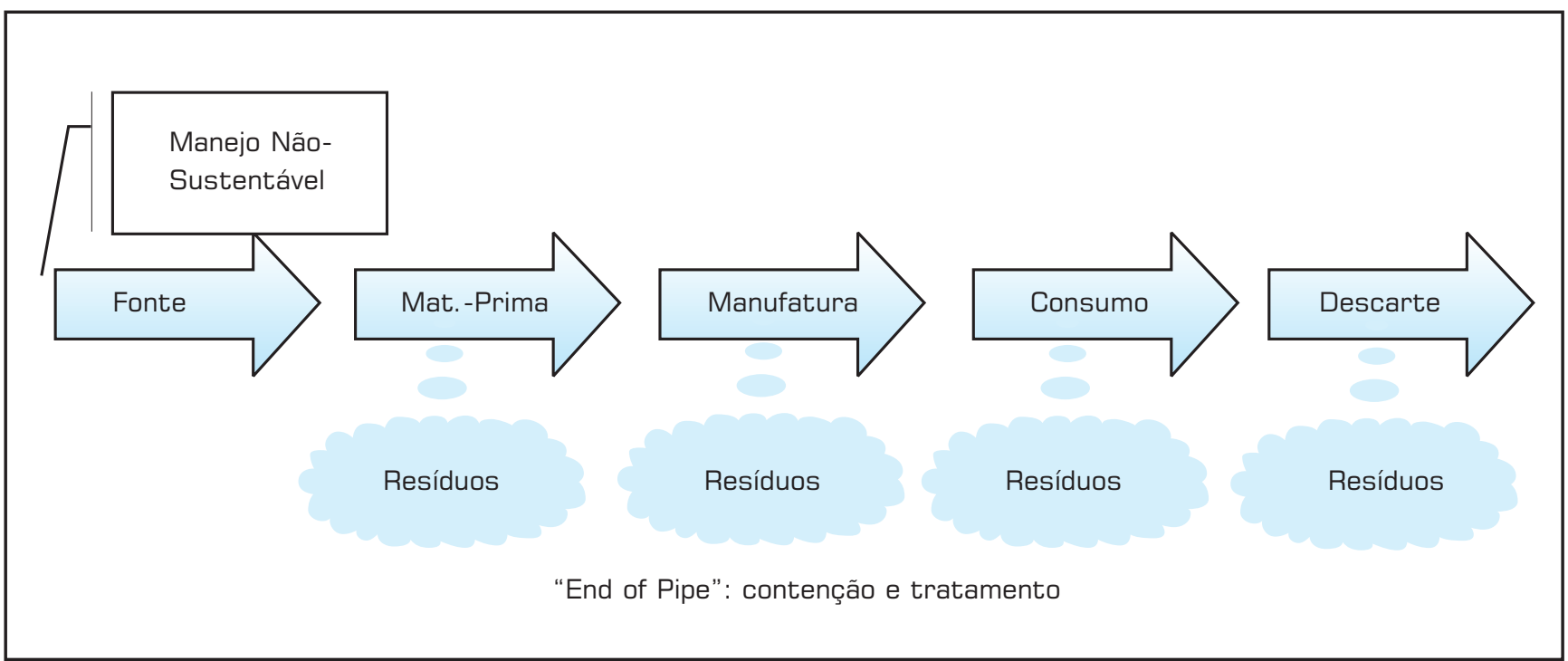

Figura 4: Modelo industrial não-linear — Furtado et al. [2001).

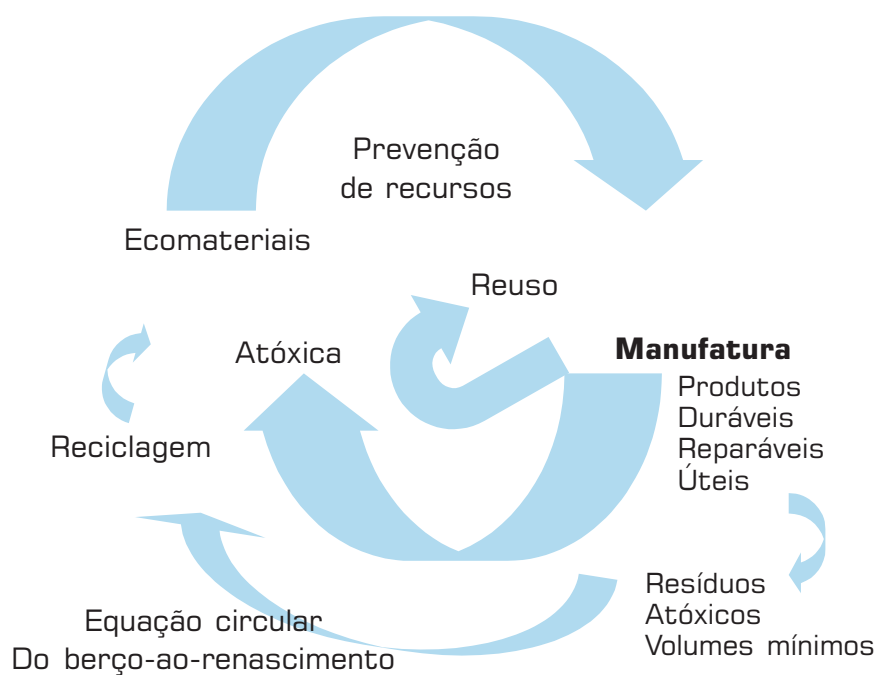


pansão de seus negócios. Entretanto, há recursos e instrumentos mais poderosos para as empresas que procuram mudar seu patamar no tratamento das questões ambientais".

De maneira resumida, de acordo com Donaire (1995), a carta de princípios de "gestão ambiental responsável" da International Chamber of Commerce - ICC envolve os seguintes pontos: 1-Prioridade organizacional; 2-Gestão integrada (ecogestão); 3-Compromisso com a melhoria dos processos; 4-Educação de recursos humanos; 5-Prioridade de enfoque; 6-Produtos e serviços nãoagressivos; 7-Orientação do consumidor; 8-Equipamentos e operações para eficiência ambiental; 9-Pesquisa sobre impactos ambientais; 10-Enfoque preventivo; 11 Orientação de fornecedores e subcontratados; 12-Planos de emergência; 13-Transferência de tecnologia limpa; 14-Contribuição ao esforço comum; 15-Transparência de atitudes; e 16-Atendimento ao público e comunicação ambiental. Uma análise desses princípios indica que os itens (2), (3), (6), (8), (10) e (13) estão diretamente correlacionados com a área de gestão da tecnologia de produtos e processos nas empresas.

Em seus estudos conceituais Furtado; Furtado (1997) indicaram que "produção limpa consiste em modelo de administração industrial para reorientar a geração de bens e serviços, segundo a visão de Sistema de Produto". Os princípios da Produção Limpa (Clean Production) surgiram nos anos 80 como proposta da organiza-

\section{ção ambientalista internacional}

"Greenpeace", na campanha para mudanças mais profundas do comportamento industrial. Essa idéia ganhou maior visibilidade a partir de 1989, quando a agência da ONU dedicada ao meio ambiente - PNUMA - Programa das Nações Unidas para o Meio Ambiente criou o programa de Produção Mais Limpa (Cleaner Production). Esses dois conceitos, segundo Furtado; Furtado (1997) podem ser resumidos como:

“- Produção Mais Limpa (Segundo o PNUMA): Processo: - conservação de materiais, água e energia; eliminação de materiais tóxicos e perigosos; redução da quantidade e toxicidade de todas as emissões e resíduos, na fonte, durante a manufatura. Produto: - redução do impacto ambiental e para saúde humana, durante todo o ciclo, da extração da matéria-prima, manufatura, consumo/uso e na disposição/descarte final.

- Produção Limpa (Segundo a GREENPEACE): Processo: - atóxico, energia-eficiente; utilizador de materiais renováveis, extraídos de modo a manter a viabilidade do ecossistema e da comunidade fornecedora ou, se nãorenováveis, passíveis de reprocessamento atóxico e energia-eficiente; não poluidor durante todo o ciclo de vida do produto; preservador da diversidade da natureza e da cultura social; promotor do desenvolvimento sustentável. Produto: - durável e reutilizável; fácil de desmontar e remontar; mínimo de embalagem; utilização de materiais reciclados e recicláveis".

Em resumo, o conceito de "produção limpa" questiona e propõe a eliminação ou a substituição do modelo industrial linear clássico (Figura 3), baseado no end-of-pipe, pelo modelo não-linear circular (Figura 4), de maior eco-eficiência e eficácia, ao defender a prevenção da geração de resíduos e promover maior poupança de água e energia. Segundo Jackson (1993) "o conceito de produção limpa envolve três princípios básicos: 1-visão do sistema global de produção; 2-aplicação dos princípios fundamentais (precaução, prevenção, integração e controle democrático); e 3-responsabilidade continuada do produtor". Assim, há necessidade de incorporação de conceitos ligados à gestão ambiental dentro das práticas de gestão da tecnologia para produtos e processos.

\section{om relação às microtecnologias de produto e de processo, as tecnologias principais e complementares poderão influenciar aspectos de meio ambiente}

A interligação entre a gestão da tecnologia e a gestão ambiental na empresa não recai obrigatoriamente no que se tem denominado de "engenharia ecológica", cujos conceitos são abordados por Mitsch ; Jorgensen (2003) e bem diferenciados da engenharia ambiental por Allen et al. (2003). Nesse campo, as tecnologias embutidas no processo produtivo são definidoras, e indicam ou não o direcionamento da ecoeficiência do sistema como um todo.

A Figura 5 apresenta uma esquematização do sistema de operações onde a função principal é a manufatura. A fase I está relacionada à matéria-prima e insumos, etapa essa também importante sob o aspecto ambiental, mas fora do escopo do presente trabalho. Com relação à fase II, o processo de produção poderá envolver várias microtecnologias, cada uma com sua tecnologia principal e tecnologias complementares, influenciando a geração de resíduos diretos, o uso de energia e outras utilidades, e a geração de resíduos indiretos, com reciclagem ou não. A fase III envolve o produto gerado no processo, com valor agregado ou não de tecnologia. No caso de existir valor agregado, sua microtecnologia poderá ser desmembrada na tecnologia principal e tecnologias com- 
plementares, podendo ocorrer ou não eliminação de resíduos na operação do produto, como por exemplo no caso do descarte de água com sabão em máquinas de lavar roupas, na emissão de gases poluentes por motores de combustão interna etc. No caso da máquina de lavar roupas, a tecnologia principal usada na de eixo horizontal é diferente daquela usada em uma máquina de lavar com eixo vertical. Essa diferença tem grandes implicações, pois a de eixo horizontal utiliza em média $1 / 4$ do sabão em pó, 1/3 da água e 1/3 da energia, em comparação com a de eixo vertical. Isso significa menor volume de efluentes (água e sabão), e menor consumo de energia, ou seja, maior eficiência e eficácia sob o ponto de vista do meio ambiente. Alguns países, como os Estados Unidos da América, e outros da União Européia, têm incentivado o uso de máquinas de lavar roupas com eixo horizontal dentro de programas de conservação de energia. Ao término de sua vida útil os produtos são descartados ou usados como sucata para outros processos industriais.

Considerando os diferentes conceitos analisados, referentes às dimensões gestão da tecnologia e gestão ambiental, e tendo como embasamento o modelo conceitual utilizado, procedemos ao desdobramento de cada uma dessas dimensões de acordo com os Quadros 1 e 2, permitindo dessa forma delinear os vários aspectos a serem abordados e pesquisados nas empresas, através de questionários e entrevistas, cujo conteúdo incorpora vários conceitos reconhecidos na literatura e na prática para a excelência de comportamento da organização nesses campos. Os aspectos da conservação de energia também foram considerados durante a pesquisa, e merecem uma análise em separado, pela sua amplitude, cujos resultados serão divulgados posteriormente.

\section{Metodologia}

A caracterização de uma pesquisa, como pura ou aplicada, mesmo envolvendo as áreas exatas ou sociais, tem sido modificada com outros conceitos, entre eles aqueles propostos por Phillips ; Pugh (1989), com as categorias: 1 - pesquisa exploratória (exploratory research), com significado de exploração; 2 - pesquisa comprovação ou teste (testing-out research), que lida com os limites de uma proposta já generalizada, testando e analisando aspectos envolvidos dentro das condições de contorno anteriormente estabelecidas; e 3 - pesquisa solução de problemas (problem-solving research), que envolve problemas particulares no mundo real. O presente trabalho de pesquisa, de ordem qualitativa, pode ser enquadrado como "pesquisa de comprovação", embora alguns aspectos estejam inseridos na "pesquisa solução de problemas".

Figura 5: Esquematização dos pontos-chave das microtecnologias de produto/processo.

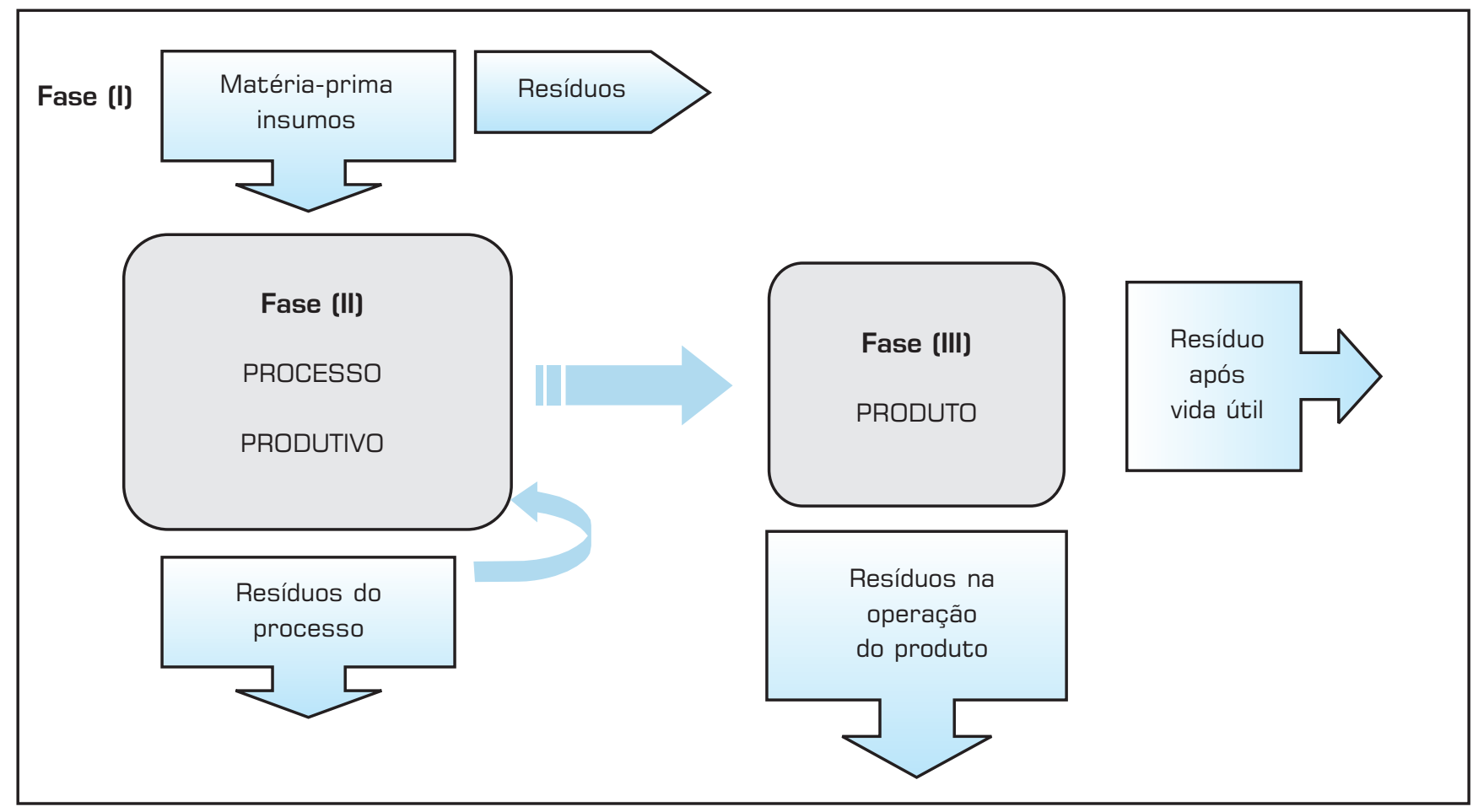


A pesquisa organizacional envolve a indução de conhecimentos práticos relacionados à eficácia organizacional. A natureza da pesquisa organizacional pode envolver abordagem quantitativa ou qualitativa, ou ambas. A abordagem quantitativa, de acordo com Bryman
(1989) assemelha-se a um processo "científico" para condução de pesquisa. O termo "científico" é vago e controvertido, mas os pesquisadores em metodologia o consideram como uma abordagem sistemática para investigação, onde o mínimo requerimento está na coleção

Quadro 1: Desdobramento da dimensão gestão da tecnologia.

\begin{tabular}{|l|}
\hline \multicolumn{1}{|c|}{ ASPECTOS DA DIMENSÃO GESTÃO DA TECNOLOGIA } \\
\hline - Grau de satisfação dos funcionários e clientes com as tecnologias usadas na empresa \\
\hline - Tempo de utilização das atuais tecnologias de produto e processo \\
\hline - Acompanhamento das tecnologias de produto e processo dos concorrentes \\
\hline - Área na empresa de prospecção tecnológica, aquisição ou licenciamento de tecnologia \\
\hline - Natureza das tecnologias da empresa: domínio público, patenteadas ou outras \\
\hline - Desenvolvimento próprio ou não das tecnologias de produto e processo \\
\hline - Lançamento de novos produtos e melhorias em produtos e processos \\
\hline - Existência de setor específico de desenvolvimento de novos produtos na empresa \\
\hline - Ordem de importância para a empresa: mercado, qualidade, tecnologia, treinamento \\
\hline - Utilização de sistema de informação tecnológica \\
\hline - Desenvolvimento de projeto parceria de pesquisa com universidade \\
\hline - Atendimento recebido nos contatos com as universidades \\
\hline - Planejamento estratégico de produto / mercado e de tecnologia \\
\hline - Indicadores para decisão de utilização de novas tecnologias de produto e processo \\
\hline - Nível de capacitação tecnológica existente na empresa \\
\hline - Valor agregado das tecnologias principais de produto e processo na empresa \\
\hline - Domínio sobre as tecnologias complementares de produto e processo na empresa \\
\hline
\end{tabular}

\section{Quadro 2: Desdobramento da dimensão gestão ambiental.}

\begin{tabular}{|l|}
\hline \multicolumn{1}{|c|}{ ASPECTOS DA DIMENSÃO GESTÃo AMBIENTAL } \\
\hline - Grau de satisfação na empresa em relação ao destino de resíduos e efluentes do processo \\
\hline - Potencial de resíduos e efluentes na produção das matérias-primas usadas na empresa \\
\hline - Estimativa dos resíduos de matéria-prima após o processo de produção e seu destino \\
\hline - Reciclagem dos resíduos de matéria-prima no processo de produção da empresa \\
\hline - Grau de importância de fatores para adoção de novas tecnologias na empresa \\
\hline - Ordem de importância dos resíduos no processo de produção da empresa \\
\hline - Destinos dos resíduos sólidos, líquidos e gasosos, provenientes do processo de produção \\
\hline - Utilização de tecnologias para redução direta de resíduos no processo de produção \\
\hline - Utilização de tecnologias de reciclagem interna de resíduos \\
\hline - Reciclagem dos produtos após vida útil \\
\hline - Estimativa dos tempos de degeneração de seus produtos no meio ambiente \\
\hline - Manutenção preventiva no processo visando a não contaminação do meio ambiente \\
\hline - Potencial de otimização das tecnologias de produto / processo para redução de resíduos \\
\hline - Reciclagem de produtos no processo de manutenção e limpeza \\
\hline - Conhecimento da ISO 14000 e certificação \\
\hline - Principais dificuldades da empresa na gestão do meio ambiente \\
\hline - Existência de descarte de resíduos ou poluentes no uso do produto da empresa \\
\hline
\end{tabular}


de dados e suas análises em relação a um problema previamente formulado. Muitas vezes as aproximações dentro do método quantitativo podem levar a resultados discutíveis, como coloca Campbell (1985), quando afirma que "o processo dedutivo do desenvolvimento de uma teoria, derivando hipóteses e testando-as para suportar procurando aprofundar vários aspectos para delineamento de tendências de comportamento.

O questionário auto-administrado envolve questões relacionadas ao desdobramento da dimensão gestão da tecnologia do Quadro 1 e da dimensão gestão ambiental do Quadro 2, com conteúdo básico envolvendo dados numéricos, escalas nominais e escalas ordinais tipo Likert (1932) apud Hayes (1992) de cinco pontos. As questões foram convertidas em variáveis e analisadas nos campos da estatística paramétrica e não-paramétrica (teste de aleatoriedade, teste de normalidade, histogramas, teste $\mathrm{c}^{2}$, mediana, distribuição de freqüências) visando indicação de tendências. De acordo com Siegel (1975), a estatística mais

ou não a teoria, apesar de aceito por todos, deve considerar também que o ideal raramente descreve a realidade". A abordagem qualitativa tem tido considerável crescimento a partir da década de 70, e de acordo com Bryman (1989) "a característica central da pesquisa qualitativa está em sua ênfase na perspectiva de comportamento do indivíduo e da organização em estudo".

O presente trabalho está concentrado na abordagem qualitativa da pesquisa organizacional, ou seja, procurando conhecer o comportamento dos indivíduos das organizações em estudo, e da própria organização, dentro dos campos correlacionados à gestão da tecnologia e à gestão ambiental. Adotando a classificação de Bryman (1989), quando conceitua "projeto de pesquisa" e "método de pesquisa", o projeto de pesquisa do presente trabalho foi desenvolvido em duas etapas. Na primeira etapa foi conduzido o "projeto de pesquisa" "levantamento survey", com o "método de pesquisa" utilizando um "questionário auto-administrado", objetivando analisar os diferentes aspectos do modelo conceitual no campo das pequenas e médias empresas. Em uma segunda etapa o "projeto de pesquisa" foi a "pesquisa qualitativa", em parte dessas pequenas e médias empresas, através do "método de pesquisa" "entrevistas semi-estruturadas", procurando enriquecer os dados já analisados no "survey" anterior, com relação ao comportamento das pessoas e das organizações.

A amostragem para o levantamento "survey" foi intencional, envolvendo 78 empresas, sendo a maioria constituída de pequenas e médias empresas tradicionais do setor de manufaturados, situadas em vários municípios do Estado de São Paulo, nas regiões da Grande São Paulo, Campinas, Piracicaba, Ribeirão Preto, Botucatu, Bauru e Marília. A pesquisa qualitativa foi conduzida após análise do "survey", com a seleção para entrevistas de 37 empresas das 78 participantes da fase anterior, tendência central da escala ordinal a mediana.

\section{ANÁLISE DOS RESULTADOS DA PESQUISA DE CAMPO}

Esse item engloba a análise da pesquisa de campo definida na metodologia anteriormente especificada. São apresentados os gráficos e as análises de todos os aspectos decorrentes do desdobramento das duas dimensões, ou seja, gestão da tecnologia e gestão ambiental, visando delinear a tendência de comportamento das empresas pesquisadas nesse campo.

\section{Gestão da Tecnologia}

Alguns aspectos da gestão da tecnologia são resumidos através da Figura 6, que indica o comportamento das empresas. Enquanto que a satisfação dos funcionários e clientes, com relação às tecnologias da empresa tem mediana 3 (razoável), a prospecção tecnológica de concorrentes e a qualificação tecnológica (treinamento) existente indicam mediana 2 (pouco satisfeito). Essas informações dão indicação de aspectos relevantes nesse campo.

O tempo de uso das tecnologias de produto e de processo nas empresas, analisado na Figura 7, parece indicar maturidade das tecnologias de produto / processo, com uma mediana de 4 e 5 anos, respectivamente. Embora poucas empresas pesquisadas têm produtos de elevado conteúdo tecnológico, essa mediana de 4 anos pode ser considerada relativamente alta. Com relação à tecnologia de processo a mediana depende da dimensão do investimento e respectiva depreciação, levando em consideração uma plataforma ou vários produtos. adequada para a escala nominal é a freqüência, e para a 
A Figura 8 indica alguns aspectos estratégicos da tecnologia, com somente $38 \%$ das empresas tendo alguma prática de planejamento estratégico nesse campo, $43 \%$ de planejamento estratégico de produto-mercado e $60 \%$ das empresas com lançamento de novos produtos nos últimos anos. Constatam-se melhorias em produtos / processos nos últimos dois anos em $65 \%$ das empresas. Ao redor de $35 \%$ das empresas utilizam consultoria e treinamento em universidades, e somente $2 \%$ com projetos de pesquisa. Outros aspectos são abordados na Figura 9, como o desenvolvimento de produto (55\% das empresas) e processo (60\%), áreas de desenvolvimento (47\%, sendo $14 \%$ específicas). Somente $8 \%$ das empresas têm áreas específicas de tecnologia, 2,8\% utilizam efetivamente sistemas de informação e $42 \%$ têm acesso a alguma informação tecnológica através de fontes de comunicação diversas.

Outro aspecto importante no campo da gestão da tecnologia está relacionado ao domínio e vulnerabilidade tecnológica das empresas estimadas pela Figura 10. Somente $24 \%$ das empresas informaram utilizar alguma tecnologia patenteada, embora $35 \%$ delas tenham indicado o uso de tecnologias de caráter restrito não patenteadas, e ao redor de $57 \%$ o uso de tecnologias de domínio

Figura 6: Aspectos da gestão da tecnologia na empresa.

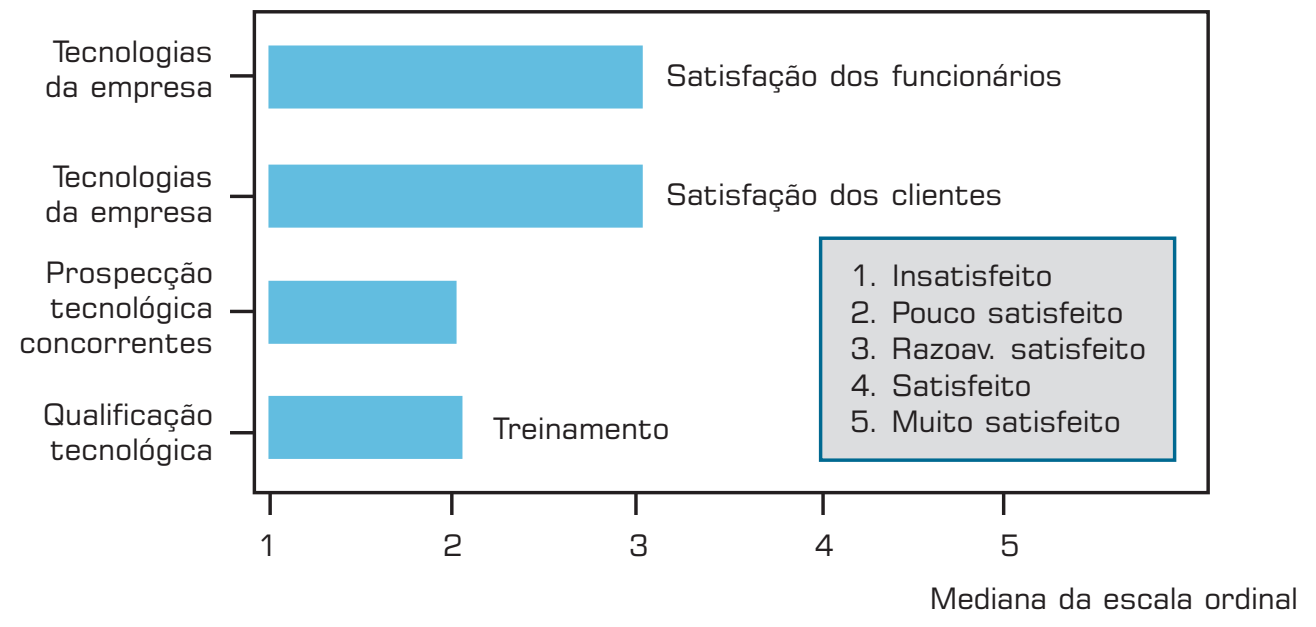

Figura 7: Tempo de uso das tecnologias nas empresas.

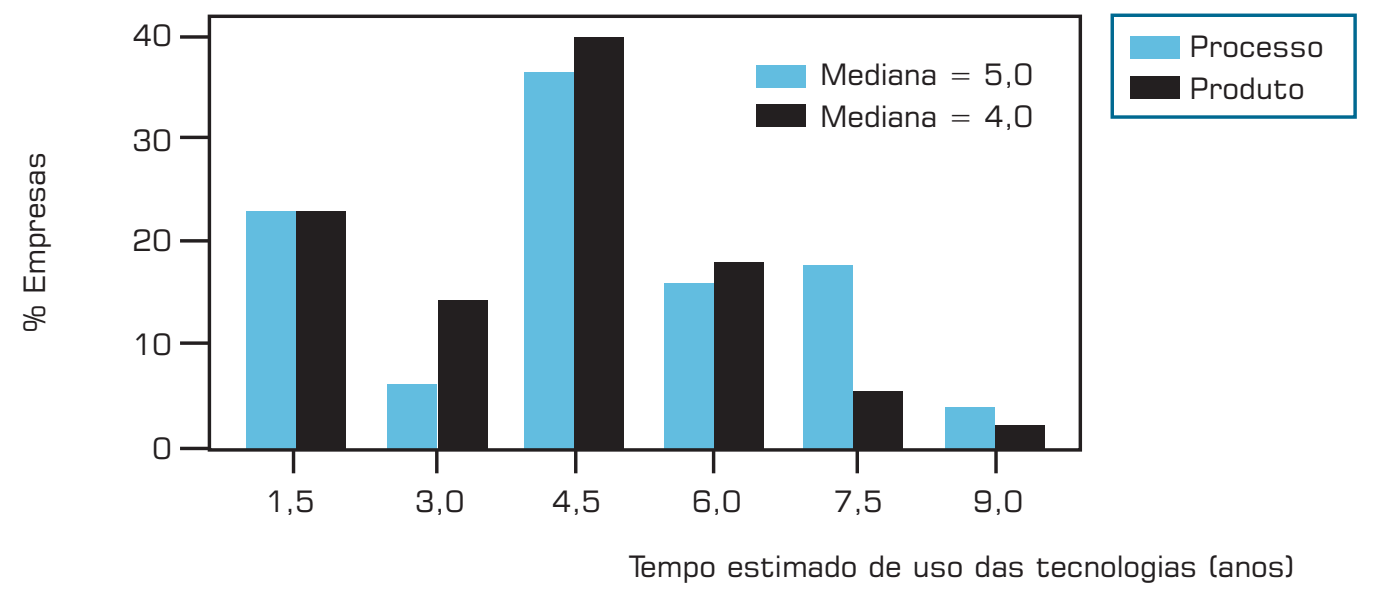


Figura 8: Aspectos estratégicos da gestão da tecnologia nas empresas.

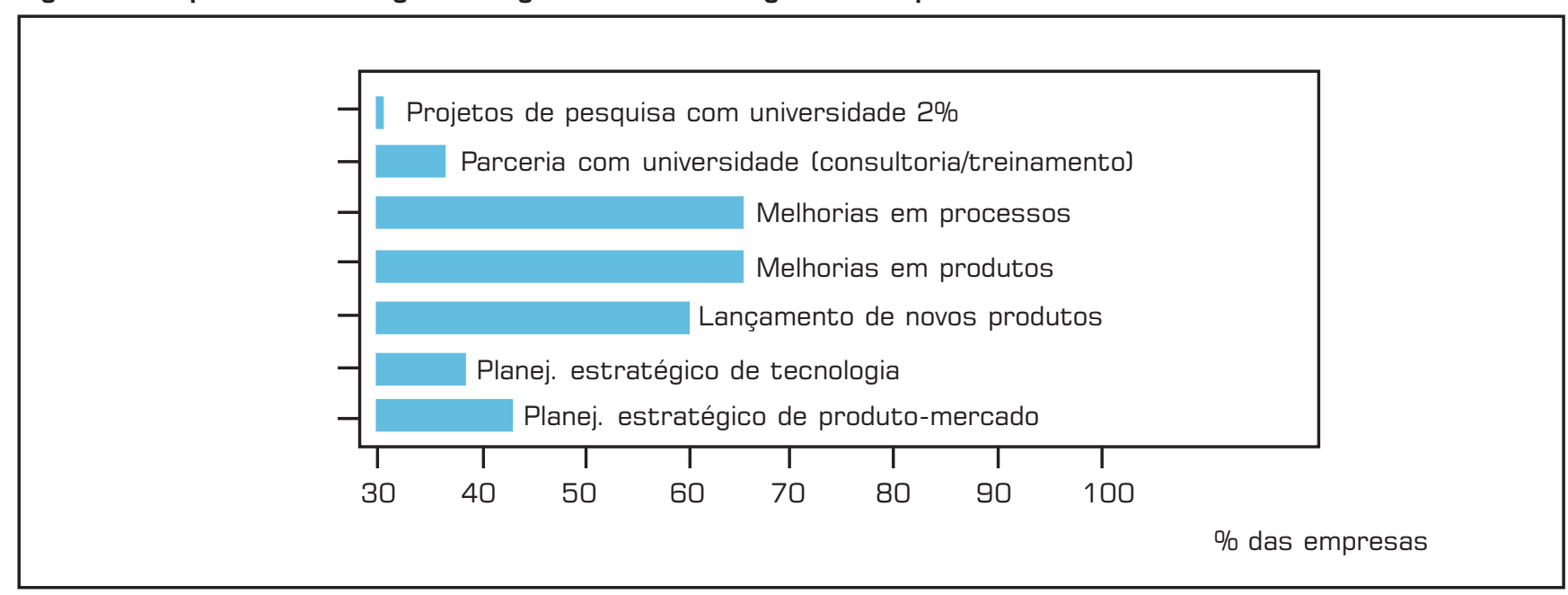

Figura 9: Aspectos da tecnologia e desenvolvimento nas empresas.

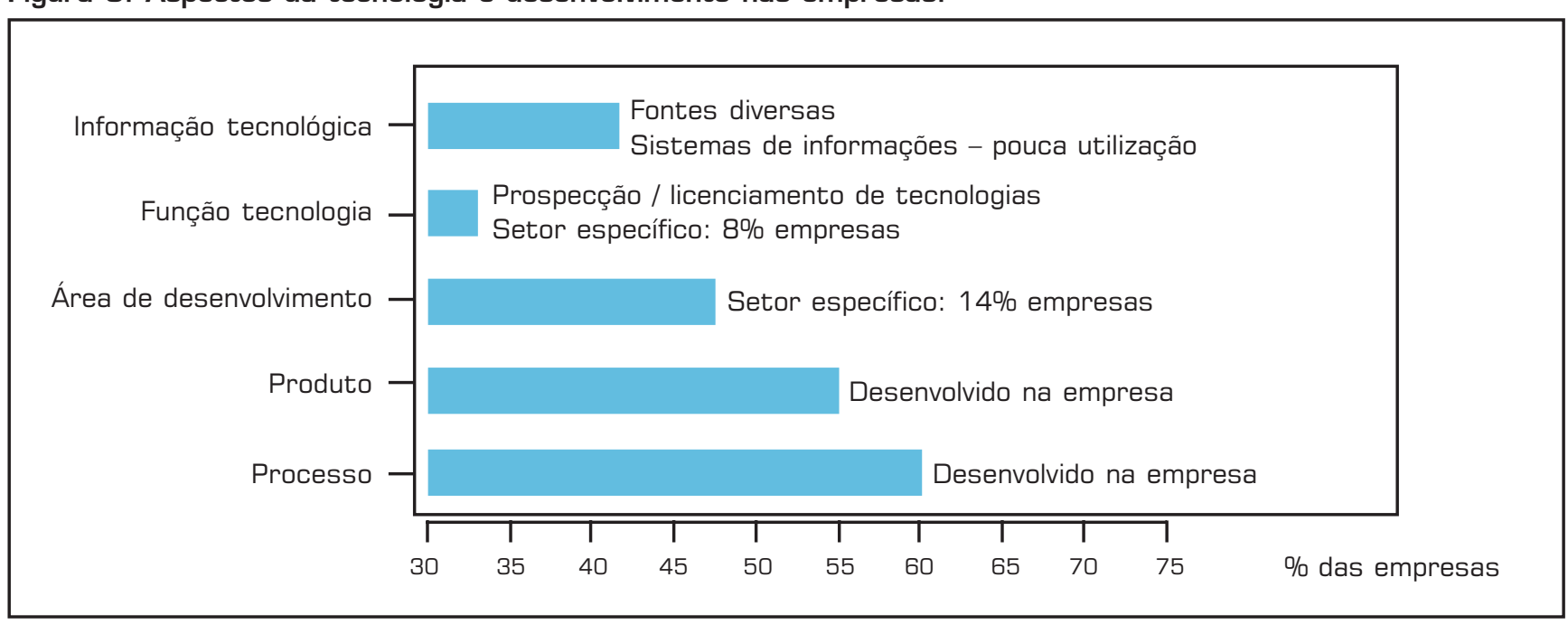

Figura 10: Domínio e vulnerabilidade das tecnologias das empresas.

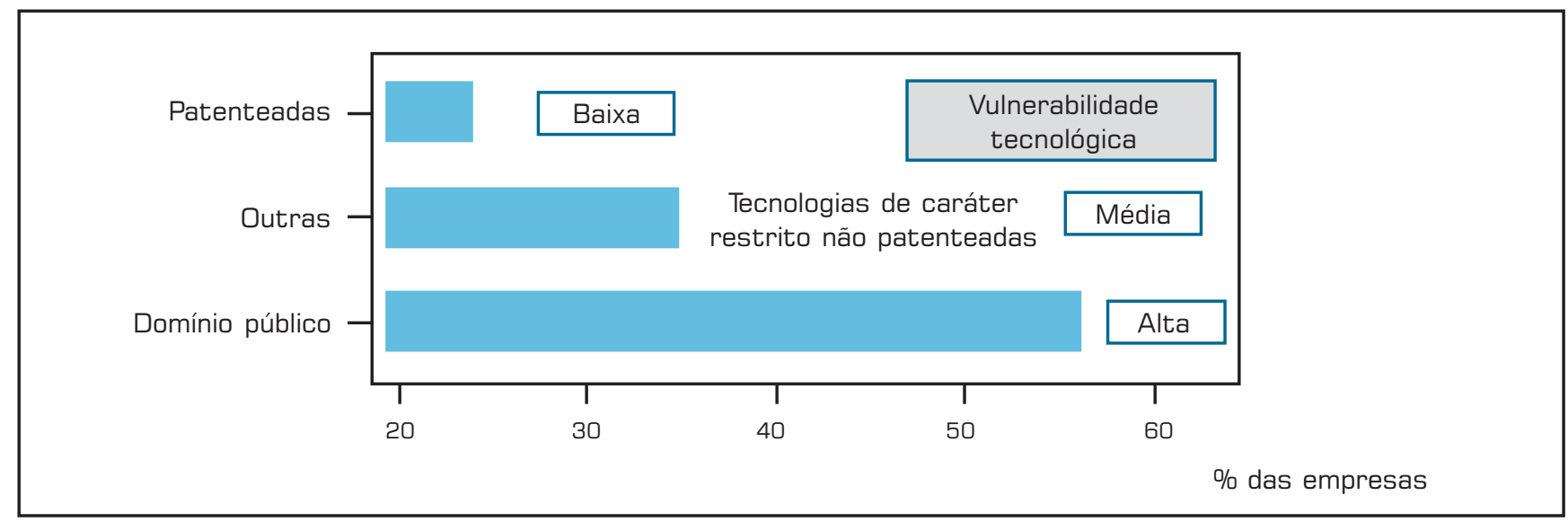


público, ou seja, alta vulnerabilidade. Portanto, ao redor de $90 \%$ das empresas utilizam tecnologias de reduzido valor agregado, sem proteção de propriedade industrial e com elevada vulnerabilidade, principalmente com relação às tecnologias de processo.

Visando delinear a ordem de importância para as empresas, na atualidade, dos fatores "mercado", "qualidade", "tecnologia" e "treinamento", a Figura 11 indica que em primeiro lugar está o "mercado e qualidade" totalizando $86 \%$ das empresas, em segundo lugar a "qualidade e tecnologia" com $75 \%$ das empresas, em terceiro lugar a "tecnolo- gia e qualidade" com $65 \%$ das empresas, e em quarto lugar "treinamento e tecnologia" com $80 \%$ das empresas.

Durante a pesquisa foi conduzida uma questão nãoadministrada relacionada aos parâmetros para uso de novas tecnologias de produto. O Quadro 3 indica o "mercado", a "concorrência" e a "redução de custos" como parâmetros de maior citação.

Dentro dos mesmos critérios, para os parâmetros de decisão de uso de novas tecnologias de processo, de acordo com o Quadro 4, as empresas indicaram maior citação para a "produtividade, "qualidade" e "redução de

Figura 11: Importância de fatores na atualidade para as empresas.

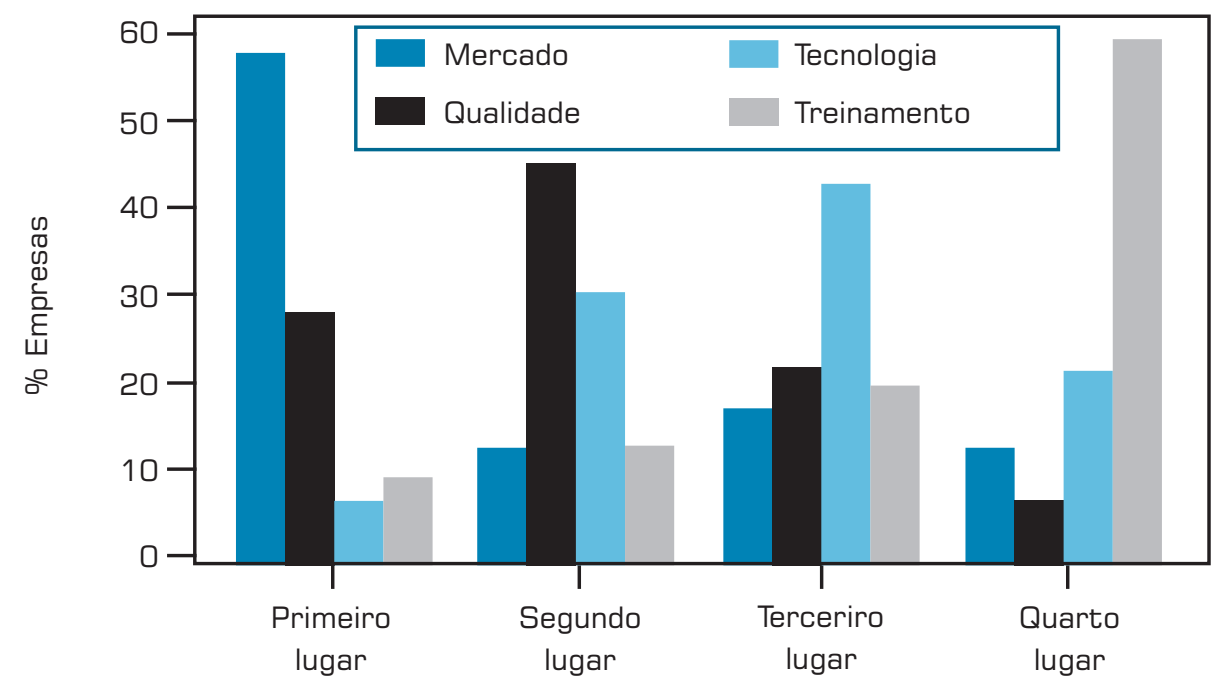

Ordem de importância

Quadro 3: Parâmetros para opção de novas tecnologias de produtos nas empresas.

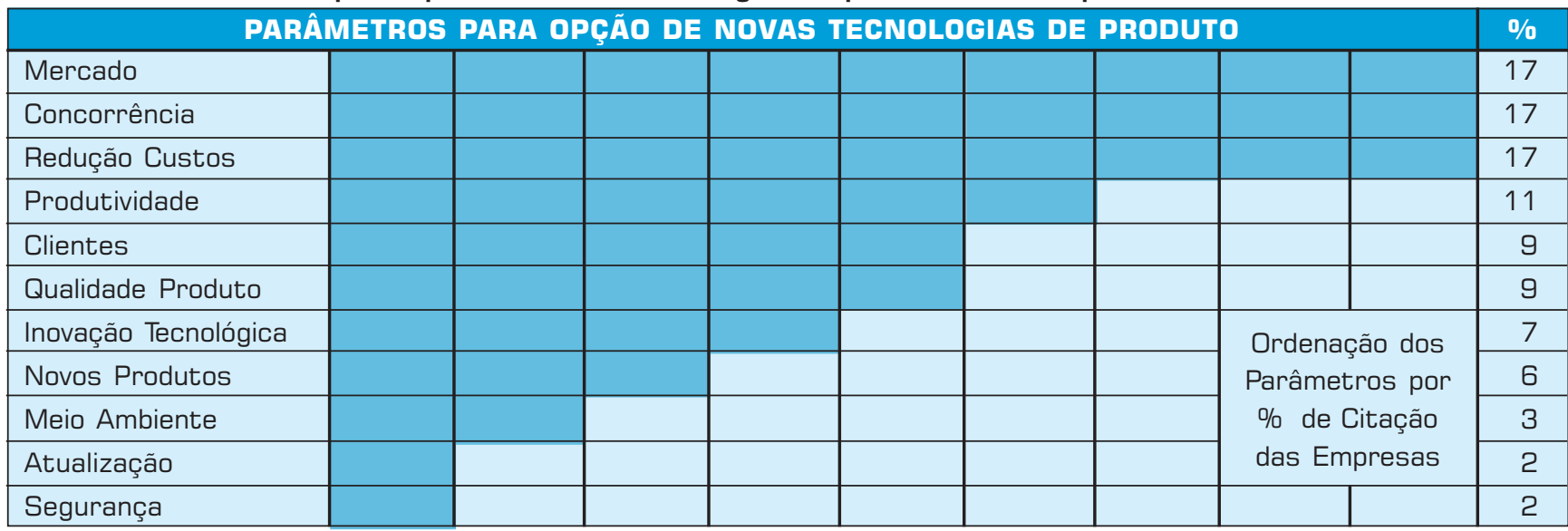


custos". Como se pode constatar, o item meio ambiente foi citado apenas por $3,7 \%$ das empresas no caso de produto e $1,7 \%$ das empresas no caso de processo, mesmo sendo o processo relevante em aspectos de geração de resíduos.

A Figura 12 indica dados da capacitação tecnológica das empresas, com mediana de 2,7 para a escala ordinal, entre "pouco satisfeito" e "razoavelmente satisfeito".
Dando continuidade à avaliação das tecnologias da empresa, o conceito de "microtecnologia" desenvolvido em Silva (2003) permite analisar esse campo com maior detalhe, pela segmentação em tecnologia principal e tecnologias complementares. Os dados das Figuras 13 e 14 foram obtidos do mesmo conjunto de empresas do presente trabalho, em pesquisa anterior. A Figura 13 indica poucas empresas com tecnologia principal de alto valor agregado, e

Quadro 4: Parâmetros para opção de novas tecnologias de processo nas empresas.

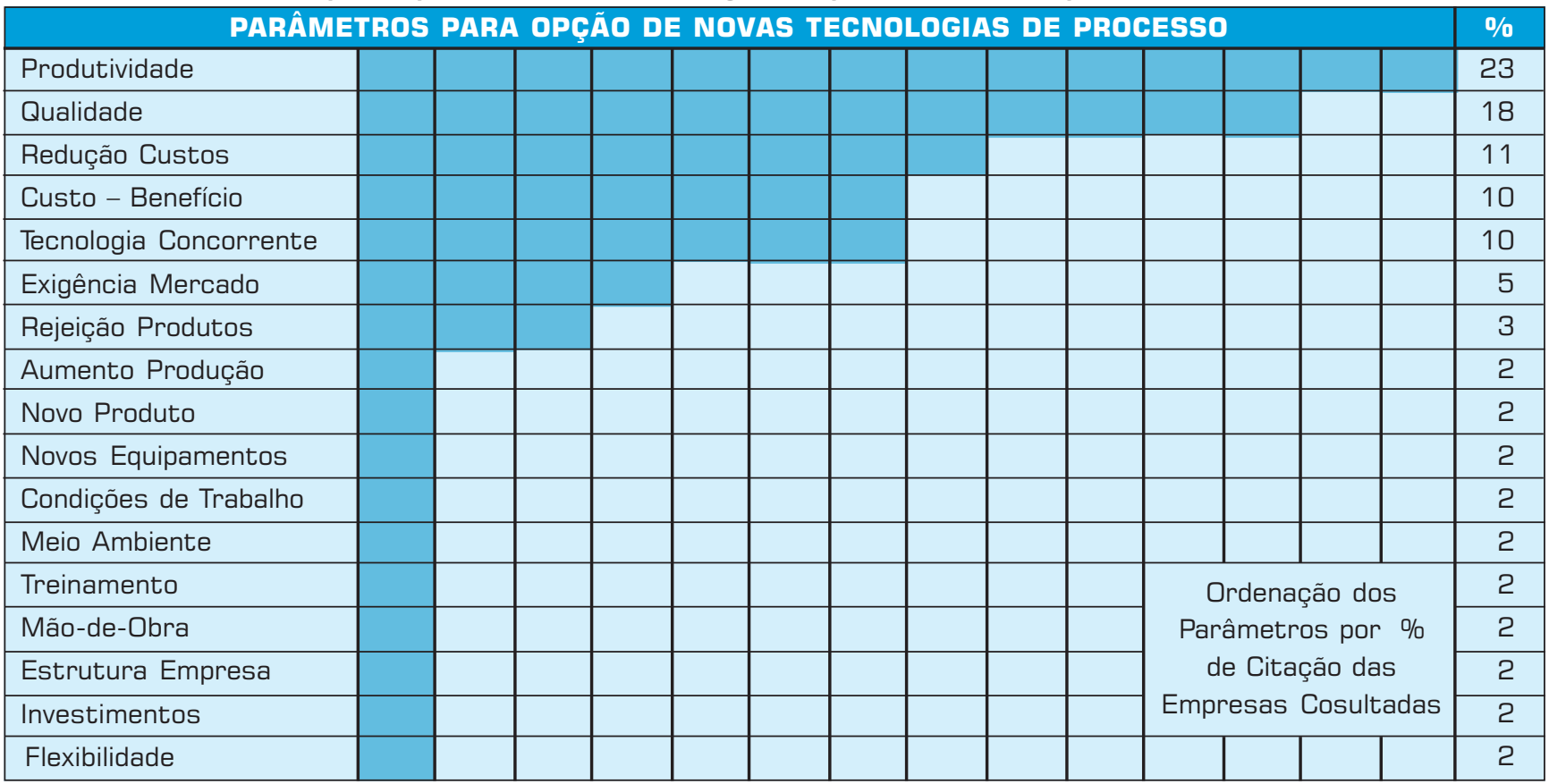

Figura 12: Auto-avaliação da capacitação tecnológica nas empresas.

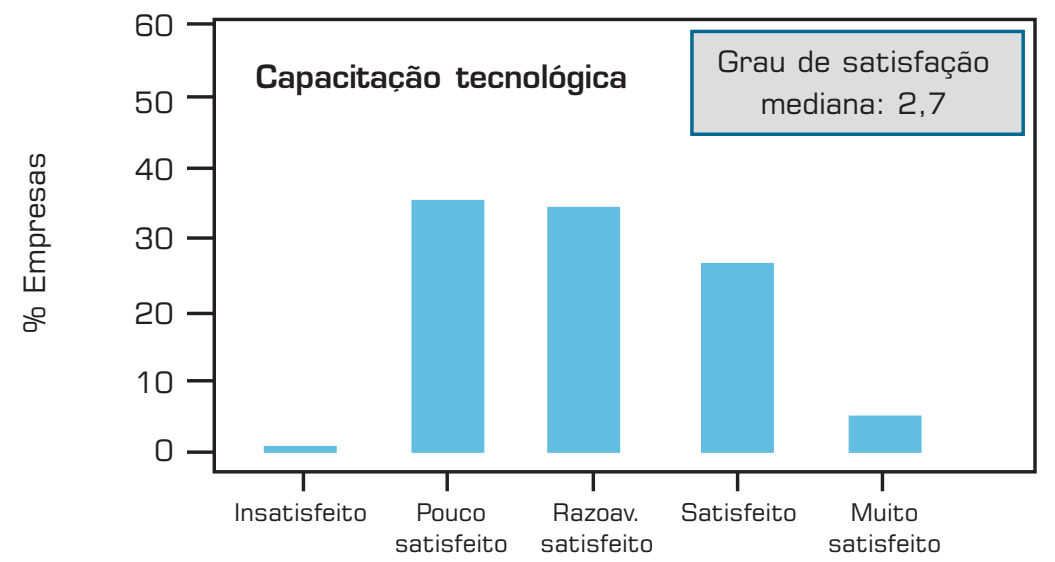

Grau de satisfação 
relativamente pouco domínio sobre essas tecnologias.

A Figura 14 indica que a maioria das empresas não tem capacitação para interferir nas tecnologias complementares de produtos / processos, geralmente fornecidas por outras empresas através de sistemas, equipamentos, acessórios ou bens de capital.

\section{Gestão Ambiental}

A pesquisa procurou delinear o comportamento das empresas em vários aspectos da gestão ambiental. A Figura 15 indica não haver problemas graves com relação aos resíduos, sob o ponto de vista dos funcionários das empresas, em função da mediana 3,0. Esse aspecto

Figura 13: Valor agregado e domínio das tecnologias principais - Silva (2003).

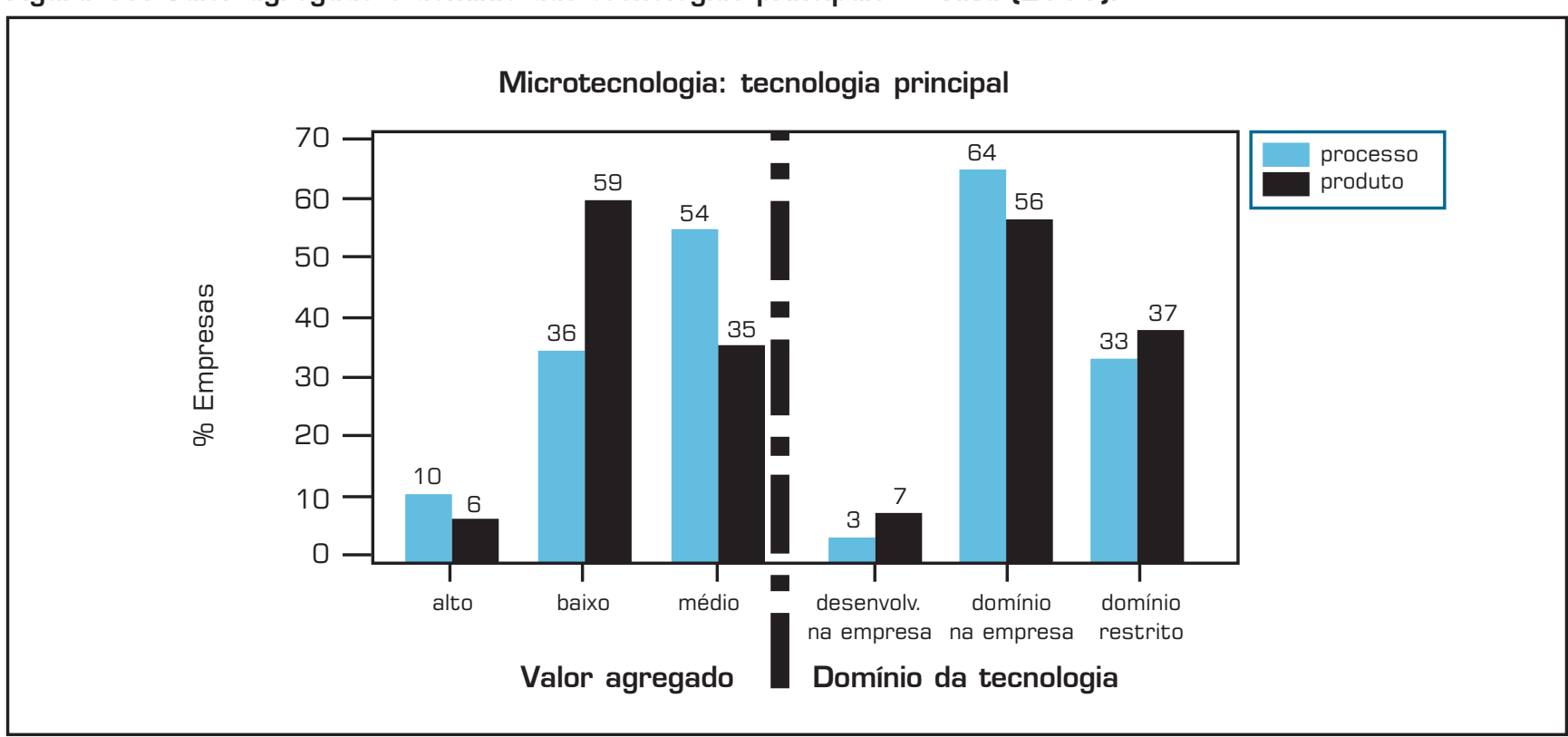

Figura 14: Domínio das tecnologias complementares - Silva (2003).

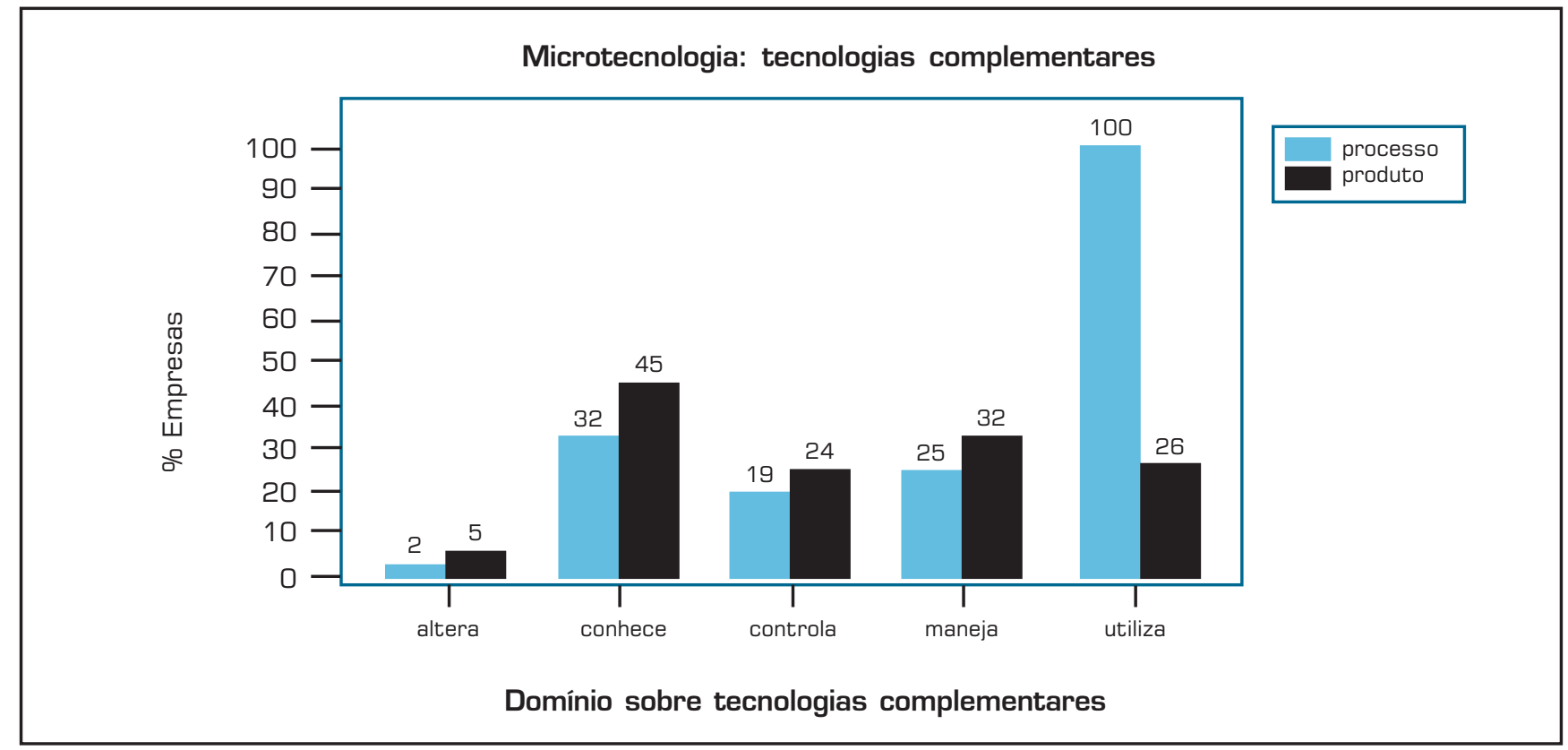


somente poderá ser comprovado após a análise de todas as questões da pesquisa nesse campo.

A análise do percentual de resíduos de matéria-prima no processo de produção das empresas indicou, de acordo com a Figura 16, uma mediana de 5\%.

A Figura 17 incorpora dados sobre resíduos na geração de matéria-prima e a reciclagem de resíduos de matéria-prima no processo de produção das empresas. Os dados indicam que $77,7 \%$ das empresas informam haver algum tipo de resíduo na fonte de matéria-prima adquirida de terceiros, com 51,8\% das empresas indicando prática de reciclagem de matéria-prima no processo de produção. Ou seja, ao redor de $50 \%$ das empresas não reaproveitam resíduos (principalmente sólidos) da matéria-prima, descartando-os como sucata para outros processos industriais ou para aterros industriais.

A Figura 18 apresenta uma complementação sobre adoção de novas tecnologias, assunto esse já abordado anteriormente nos Quadros 3 e 4, agora com questão administrada, visando delineamento no campo de meio ambiente. Como se constata, o meio ambiente recebe a indicação de somente $7 \%$ das empresas no primeiro grau de importância, $26 \%$ no segundo grau, e $8 \%$ no terceiro grau, indicando não prioridade para a maioria das empresas.

A Figura 19 analisa o grau de importância dos três principais tipos de resíduos nas empresas de manufatura, com ordem decrescente de importância.

Figura 15: Grau de satisfação existente na empresa com o destino dos resíduos.

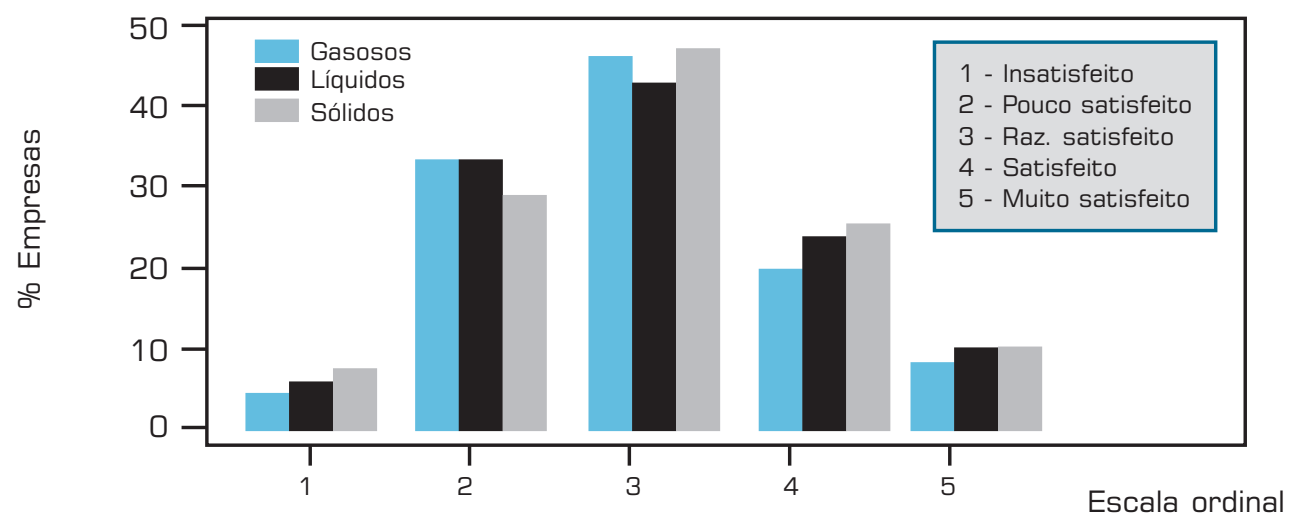

Figura 16: Resíduos de matéria-prima no processo de produção das empresas.

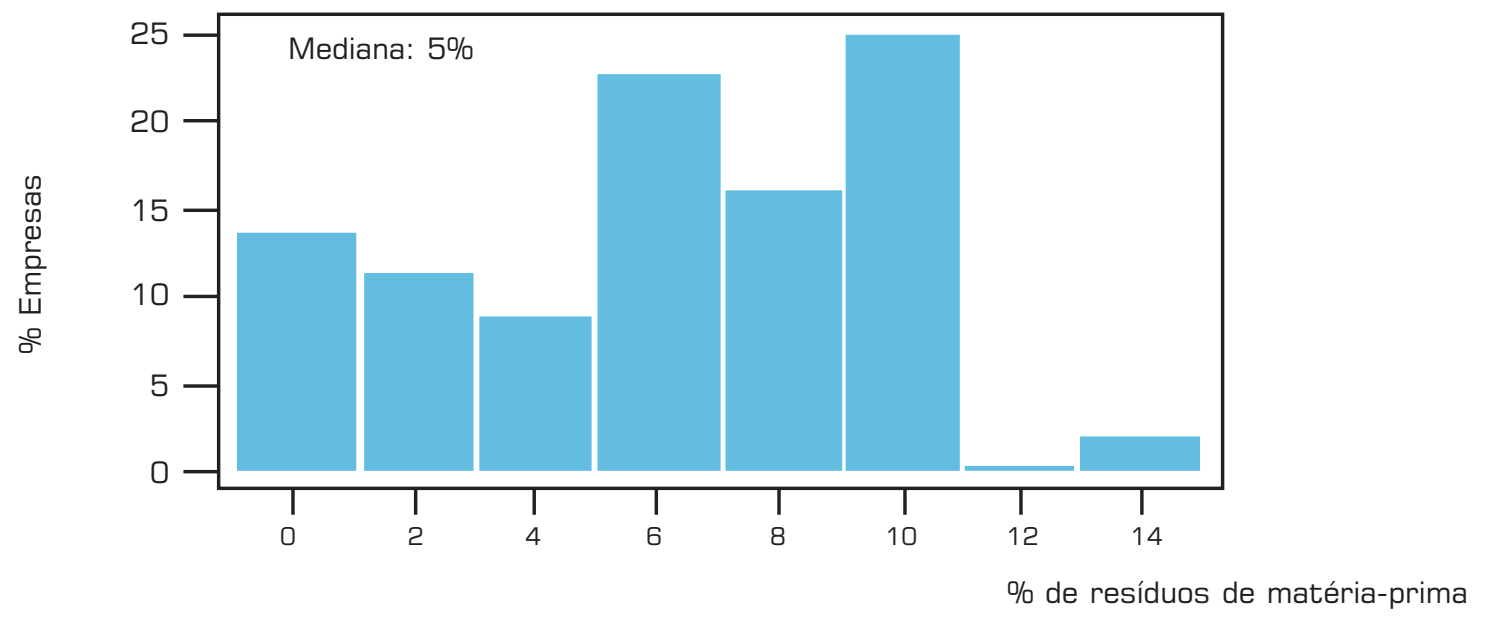


O Quadro 5 analisa os destinos dos resíduos sólidos, líquidos e gasosos, produzidos no processo, com indicação de que $50 \%$ das empresas comercializam ou reciclam resíduos sólidos, $57 \%$ tratam e/ou lançam os efluentes líquidos no esgoto/rios, e $66 \%$ das empresas lançam na atmosfera ou filtram os resíduos gasosos.
Com relação às tecnologias ou metodologias de redução de resíduos, e de reciclagem no processo, $53 \%$ e $41 \%$ das empresas fazem uso, respectivamente, de acordo com o Quadro 6. Por outro lado 78\% das empresas indicam que há potencial de otimização das tecnologias de produto e processo visando redução de resíduos no processo de produção.

Figura 17: Matéria-prima: potencial de resíduos e reciclagem.

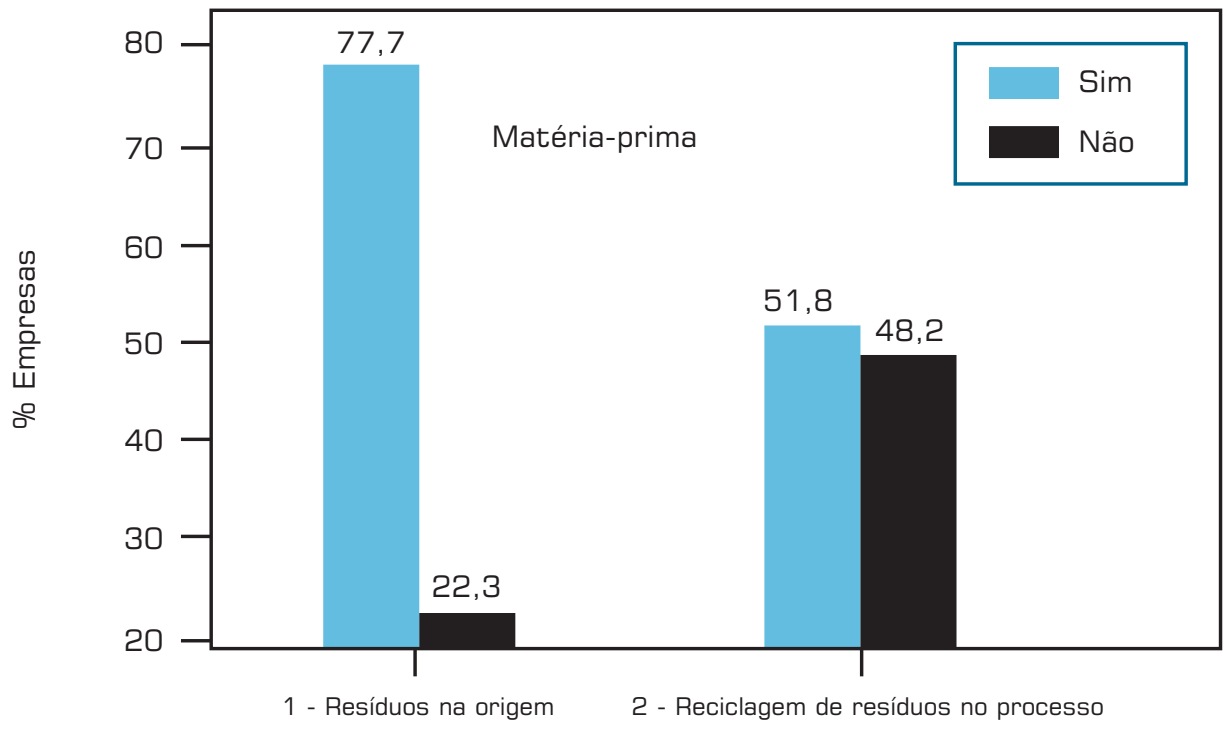

Figura 18: Fatores de decisão na adoção de novas tecnologias nas empresas.

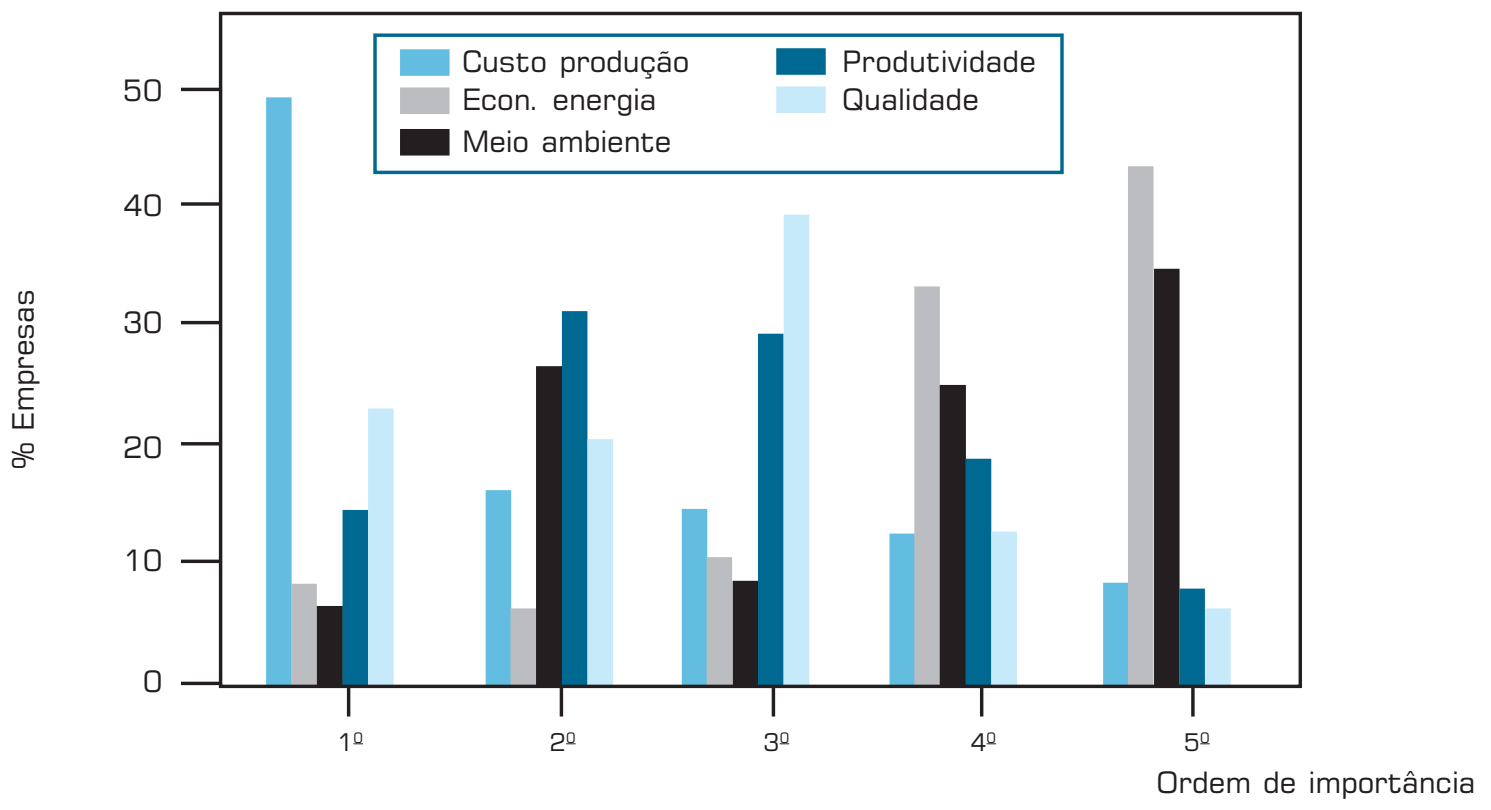


No que refere à manutenção preventiva e corretiva, a Figura 20 indica que $77 \%$ das empresas realizam manutenção contra vazamentos no processo de produção enquanto que $42 \%$ fazem a reciclagem de materiais de manutenção das instalações.

Dependendo da característica do produto, este poderá afetar o meio ambiente durante sua utilização. De acordo com a Figura 21, para $21 \%$ das empresas existe essa possibilidade e para $79 \%$ não existe. Ao redor de $50 \%$ das empresas indicam não reciclagem do produto após sua vida útil, e a outra metade reciclagem externa.

A Figura 22 apresenta uma estimativa do tempo de degeneração dos produtos das empresas no meio ambi- ente, indicando uma mediana de 10 a 50 anos, cujo contexto é muito complexo para discussão, tendo em vista a ampla variedade de produtos das empresas de manufatura consultadas.

A Figura 23 apresenta informações relacionadas à norma ISO 14000. Constata-se que $16,8 \%$ das empresas consultadas desconhecem o conteúdo dessa norma ambiental e somente $4,5 \%$ das empresas têm a certificação. Apesar de ter ocorrido melhoria nos dados das empresas nos últimos três anos, ainda é limitada essa certificação. Como já assinalamos, a certificação em si não garante a gestão ambiental do sistema produtivo nas empresas.

Figura 19: Grau de importância dos resíduos nas empresas.

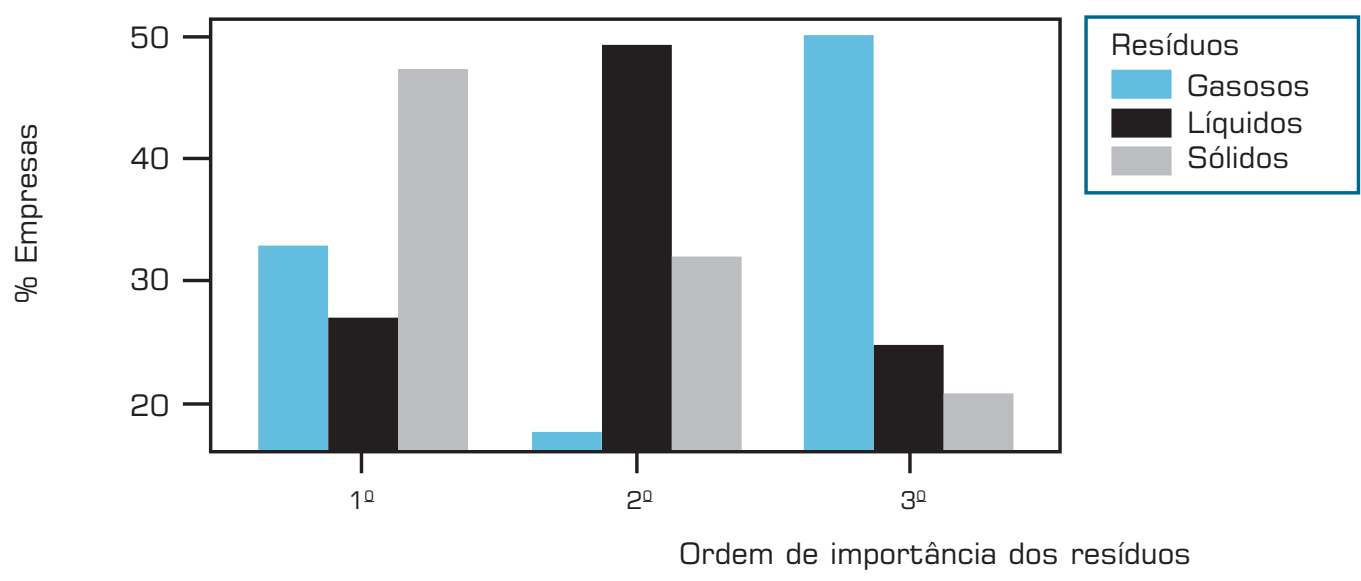

Quadro 5: Destinação dos resíduos sólidos, líquidos e gasosos das empresas.

\begin{tabular}{|l|r|l|c|l|c|}
\hline \multicolumn{5}{|c|}{ DESTINOS DOS RESÍDUOS DO PROGESSO DE PRODUÇÃO NAS EMPRESAS } \\
\hline \multicolumn{1}{|c|}{ Sólidos } & $\%$ & \multicolumn{1}{|c|}{ Líquidos } & $\%$ & \multicolumn{1}{c|}{ Gasosos } & $\%$ \\
\hline Comercialização & 26 & Tratamento & 32 & Atmosfera & 40 \\
\hline Reciclagem & 24 & Esgoto / Rios & 25 & Filtros & 26 \\
\hline Aterro & 16 & Reciclagem & 17 & Tratamento & 22 \\
\hline Lixo Industrial & 10 & Descarte & 5 & Reciclagem & 7 \\
\hline Lixão & 8 & Empresa Reciclagem & 2 & & 4 \\
\hline Ração Animal & 6 & Fertilizante & 2 & & \\
\hline Fertilizante & 4 & Irrigação & 2 & & \\
\hline Queima & 4 & Compostagem & 2 & & \\
\hline Geração Vapor & 2 & Inseticidas & & & \\
\hline
\end{tabular}


O Quadro 7 indica as principais dificuldades das empresas consultadas em gestão ambiental, extraídas de questões não-administradas. As dificuldades mais proeminentes podem ser enumeradas: tecnologias de processamento de resíduos, custos operacionais e de manutenção do sistema e legislação/regulamentação.

\section{Gestão da Tecnologia e Gestão Ambiental na Matriz de Relacionamentos}

Após a análise dos dados de campo, referentes à gestão da tecnologia e gestão ambiental nas empresas, se considerarmos a Matriz de Relacionamentos das Atividades na Organização, proposta em Silva (2003), pode-

Quadro 6: Uso de tecnologias de redução de resíduos/reciclagem e otimização.

\begin{tabular}{|c|c|}
\hline $\begin{array}{l}\text { TECNOLOGIAS DE REDUÇAO DE } \\
\text { Uso de Tecnologias de Redução de Resíduos }\end{array}$ & Uso de Tecnologias de Reciclagem no Processo \\
\hline $53 \%$ (empresas) utilizam & $41 \%$ (empresas) utilizam \\
\hline Tecnologias ou Procedimentos & Tecnologias ou Procedimentos \\
\hline Desulfitação & Decantação \\
\hline Controle Biológico & Clarificação \\
\hline Eficiência Equipamento & Filtragem \\
\hline Reutilização de Águas & Moagem / Aglomerados \\
\hline Aspiração e Lavagem & Neutralização \\
\hline Estação Tratamento & Tratamento / Reciclagem \\
\hline Caixas de Resíduos & Evaporação / Reutilização \\
\hline Filtragem & Queima \\
\hline Gerenciamento de Resíduos & Irrigação \\
\hline Reciclagem & Ração Animal \\
\hline Tecnologia Moldes & Reprocessamento \\
\hline Treinamento & Tratamento Biológico \\
\hline Obtenção Subprodutos & \\
\hline \multicolumn{2}{|c|}{ Otimização das Tecnologias de Produto/Processo Visando Redução de Resíduos } \\
\hline $78 \%$ (empresas) Existe Potencial & $22 \%$ (empresas) Não Existe Potencial \\
\hline
\end{tabular}

Figura 20: Manutenção e aspectos de meio ambiente nas empresas.

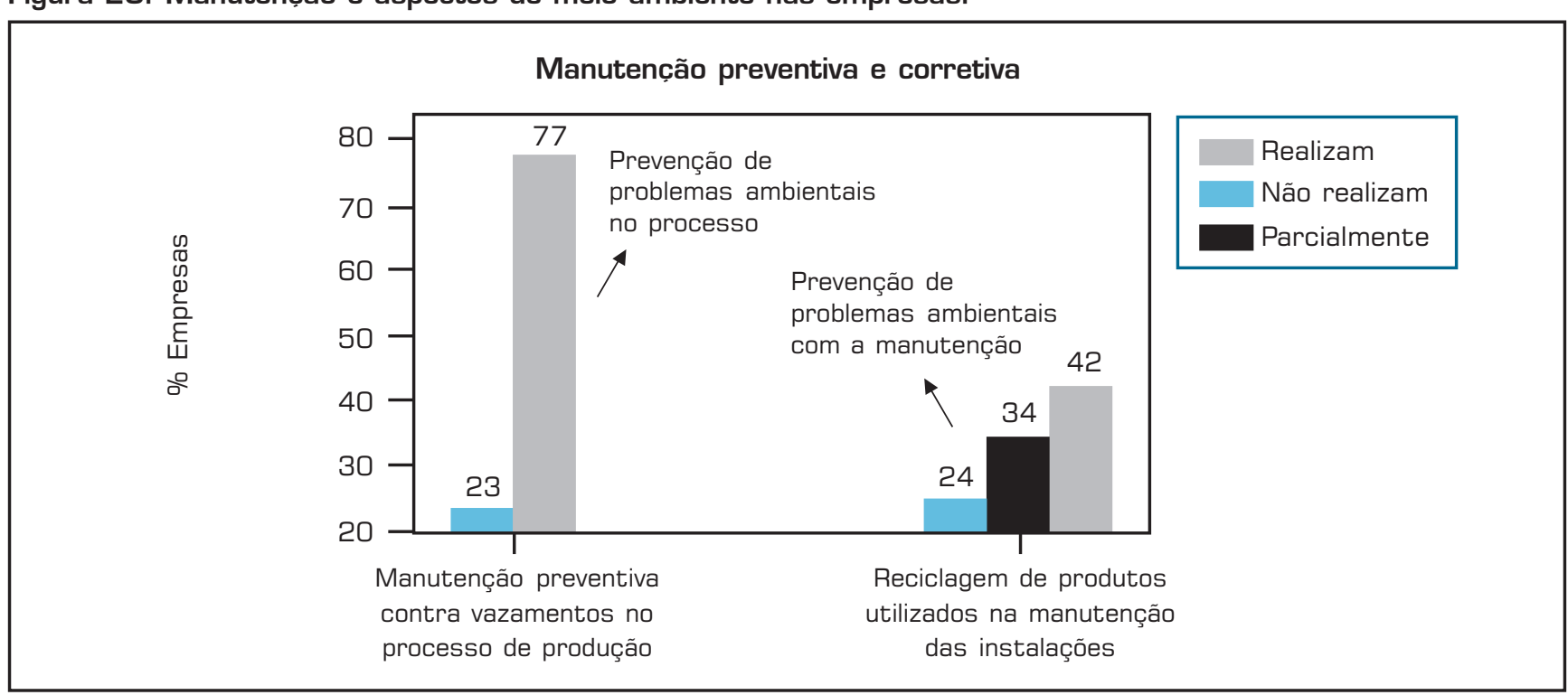


mos concluir que para a dimensão "tecnologia" não houve alterações naquelas relações. No entanto, no que se refere às dimensões "meio ambiente" e "conservação de energia", agora dentro do contexto mais amplo de gestão ambiental, contata-se uma ampliação daquelas relações com as áreas: estratégia, finanças, qualidade e produto/ mercado. Essa ampliação é decorrente da transposição do modelo linear para modelo não-linear, no contexto de meio ambiente, com visão integrada do sistema produtivo, fazendo uso de conceitos já analisados anteriormente como "Clean Production" e "Cleaner Production". Nesse contexto, as dimensões de "meio

Figura 21: Influência do produto no meio ambiente.

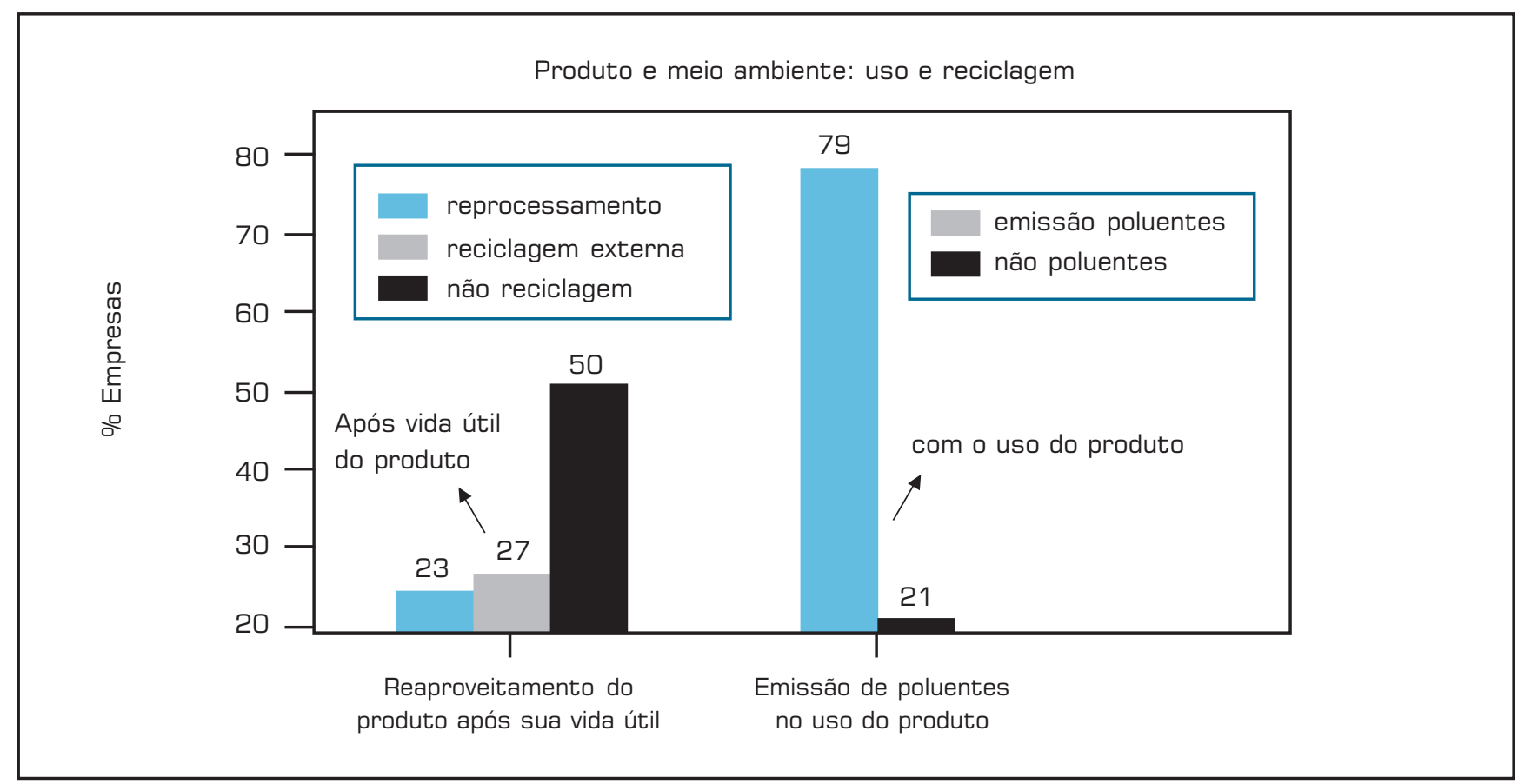

Figura 22: Tempo de degeneração dos produtos das empresas no meio ambiente.

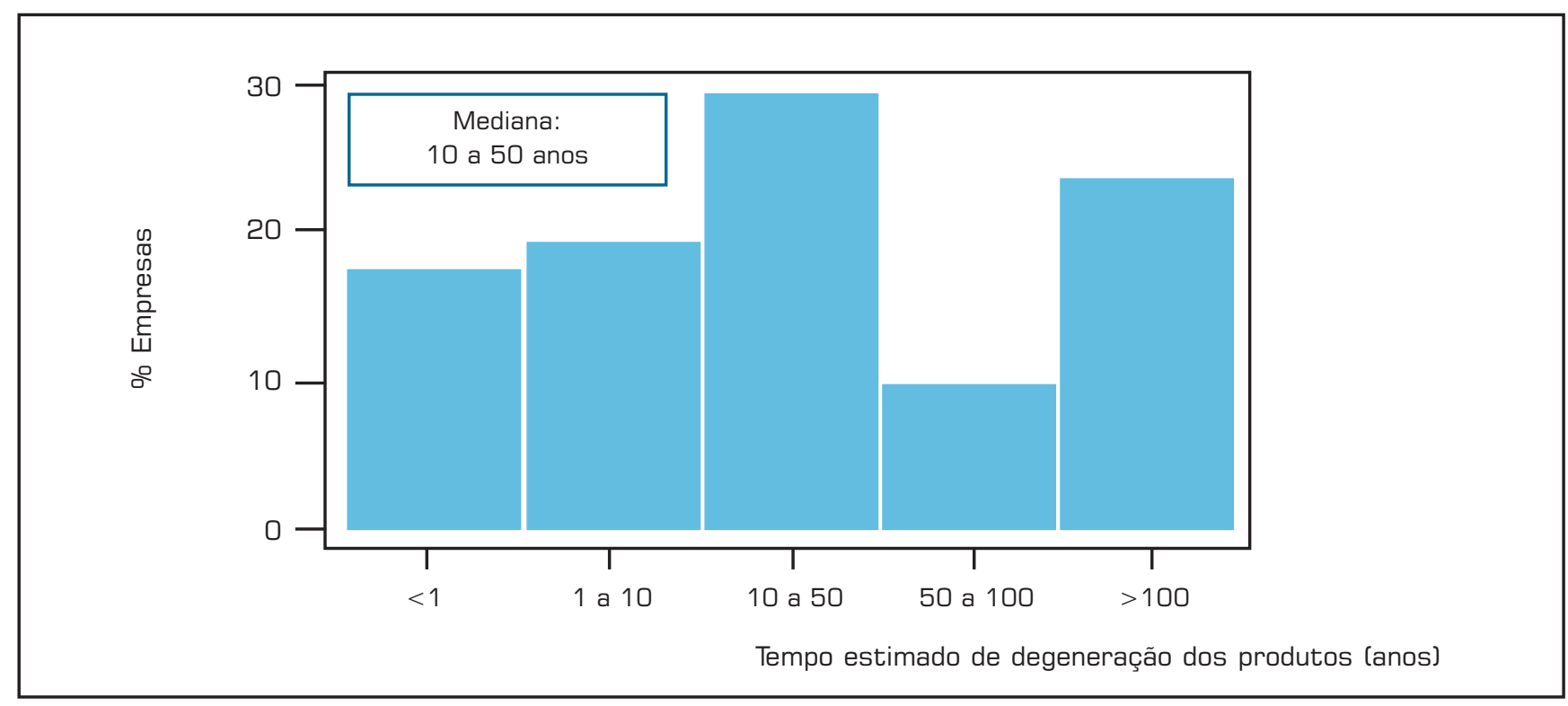


ambiente" e de "conservação de energia" estão interrelacionadas, e se incorporam às atividades rotineiras das organizações, internas e externas, com resumo da Matriz de Relacionamentos apresentado de acordo com a Figura 24 somente para essas atividades. Desta forma tem-se uma atualização da Matriz de Relacionamentos Funcionais das Empresas, de acordo com a proposta em Silva (2003).

Figura 23: ISO 14.000: conhecimento e certificação nas empresas.

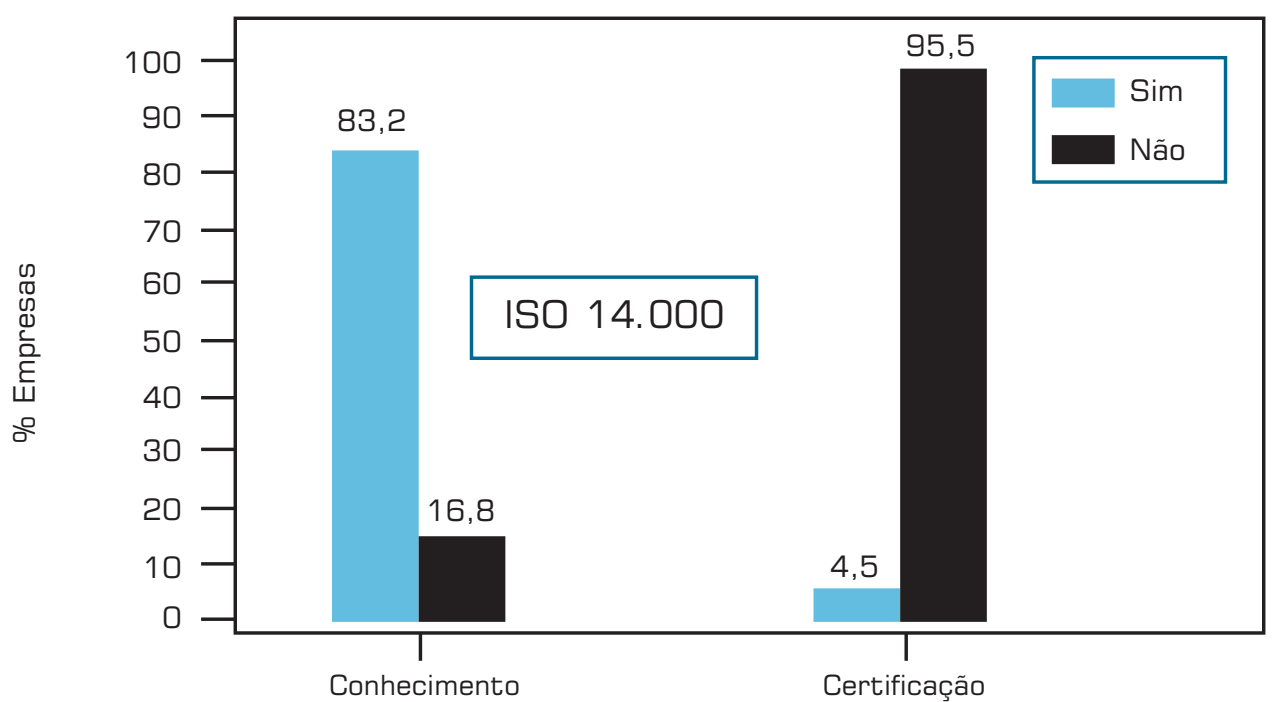

ISO 14.000

Quadro 7: Principais dificuldades das empresas na gestão ambiental.

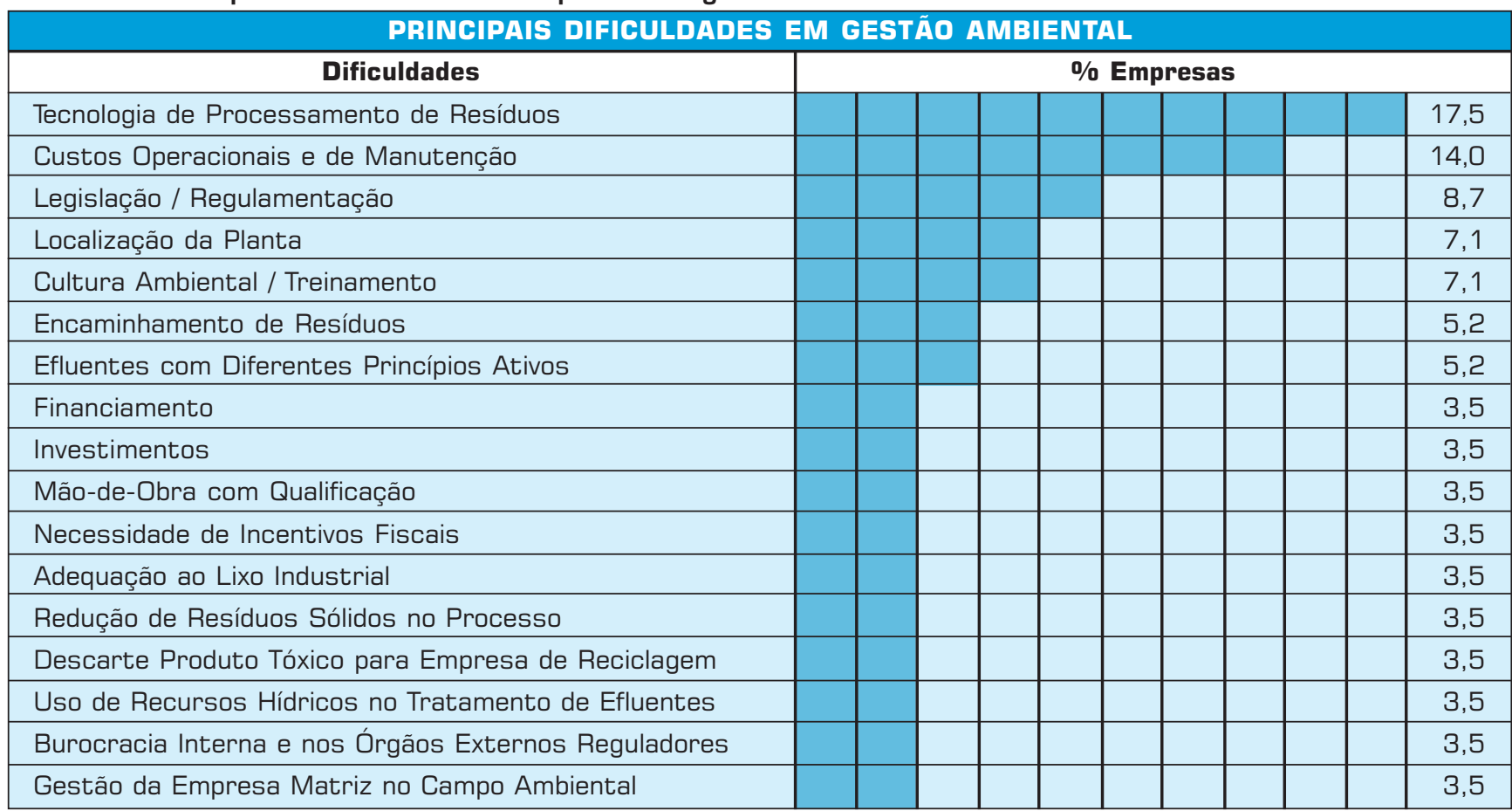




\section{CONCLUSÕES}

O presente trabalho analisou vários aspectos da gestão da tecnologia (produto/processo) em empresas de manufatura, incluindo uma nova dimensão da abordagem do termo "tecnologia", com o uso de novos conceitos como "microtecnologia" (de produto e de processo) e "macrotecnologia" (capabilidade tecnológica da organização). Ao mesmo tempo foram analisados vários aspectos relacionados à gestão ambiental nessas empresas, desde a matéria-prima até o produto final e resíduos. O trabalho envolveu "levantamento survey" e "entrevistas semi-estruturadas" em pequenas e médias empresas do setor de manufaturados. Fundamentalmente procurou-se verificar se as empresas com alguma capabilidade tecnológica apresentavam melhor desempenho no campo da gestão ambiental, em comparação com as empresas de limitada capabilidade tecnológica.

Com relação à gestão da tecnologia, os dados indicam satisfação razoável dos funcionários e clientes (ponto de vista da organização) com relação às tecnologias da empresa, embora haja pouca satisfação quanto à qualificação tecnológica e acompanhamento das tecnologias concorrentes. O tempo de uso das tecnologias nas empresas está na faixa de 4,0 a 5,0 anos, com melhorias em produtos e processos em $65 \%$ das empresas e lançamento de novos produtos para $60 \%$ delas.

Quanto a aspectos estratégicos, $42 \%$ das empresas informaram praticar planejamento estratégico de produto-mercado e $37 \%$ de planejamento estratégico de tecnologia. Somente $2 \%$ das empresas informaram ter ocorri- do alguma parceria em projetos de pesquisa com universidades, e ao redor de $2,5 \%$ informaram ter acesso a sistemas de informação.

Somente $14 \%$ das empresas informaram ter setor específico de desenvolvimento, e $8 \%$ de tecnologia, embora $60 \%$ tenham especificado o desenvolvimento de seus processos e $55 \%$ de seus produtos, na maior parte utilizando tecnologias de domínio público, como se constata pela auto-avaliação de capacitação tecnológica, situada entre "pouco satisfeito" e "razoavelmente satisfeito". As prioridades atuais das empresas estão no mercado (58\%), depois a qualidade (46\%), a tecnologia (44\%) e o treinamento $(60 \%)$.

Em questionamento não administrado para a tomada de decisão de uso de novas tecnologias, constata-se, na ordem de maior citação, o mercado, a concorrência, a redução de custos e a produtividade, para as tecnologias de produto, e a produtividade, qualidade, redução de custos e custo-benefício, para as tecnologias de processo.

Resumindo, no campo da gestão da tecnologia, podemos dizer que não se constatam grandes alterações na configuração relatada em Silva (2003) e Silva (2002 b). Em geral a maioria das empresas pesquisadas ainda não desenvolve atividades específicas nesse campo, ao contrário de empresas americanas, européias e asiáticas do setor de manufaturados. Muitas terminologias e conceitos praticados internacionalmente ainda são desconhecidos para muitas empresas. Constatam-se limitações em aspectos estratégicos e operacionais com relação às tecnologias de produto e processo, e em capabilidade tecnológica. As informações relacionadas às mi-

Figura 24: Matriz de relacionamentos na organização [Atualizada de Silva [2003)].

\begin{tabular}{|c|c|c|c|c|c|c|c|c|c|c|c|c|c|c|}
\hline \multicolumn{15}{|c|}{ GERENCIAMENTO GLOBAL DA EMPRESA } \\
\hline $\begin{array}{c}\text { Matriz de } \\
\text { Relacionamento } \\
\text { das Atividades } \\
\text { na Organização }\end{array}$ & 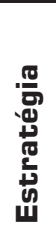 & 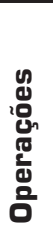 & 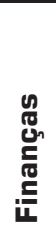 & 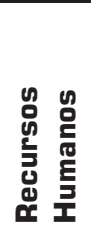 & 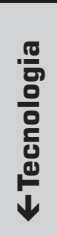 & 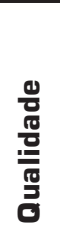 & 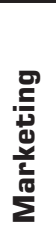 & 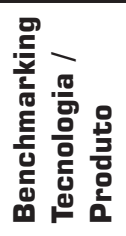 & 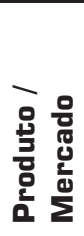 & 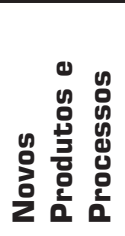 & 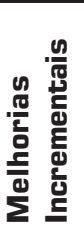 & 율 & 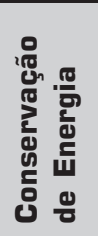 & 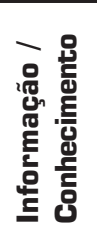 \\
\hline \multicolumn{15}{|l|}{$*$} \\
\hline \multicolumn{15}{|l|}{$*$} \\
\hline Tecnologia $\rightarrow$ & 口 & $\mathbf{\square}$ & 口 & $\mathbf{\square}$ & $\mathbf{x}$ & 口 & $\square$ & $\square$ & $\mathbf{\square}$ & - & 口 & 口 & 口 & 口 \\
\hline \multicolumn{15}{|l|}{ * } \\
\hline \multicolumn{15}{|l|}{ * } \\
\hline Meio Ambiente & 口 & $\mathbf{\square}$ & 更 & $\mathbf{\square}$ & $\mathbf{\square}$ & $\mathbf{\square}$ & $\mathbf{\square}$ & & $\mathbf{\square}$ & - & $\mathbf{\square}$ & $\mathbf{x}$ & - & $\mathbf{\square}$ \\
\hline $\begin{array}{l}\text { Conservação } \\
\text { de Energia }\end{array}$ & घ & $\mathbf{\square}$ & घ & च & घ & $\mathbf{\square}$ & $\mathbf{\square}$ & & - & च & 口 & घ & $\mathbf{x}$ & $\square$ \\
\hline
\end{tabular}


crotecnologias, de produto e processo, cristalizam essas observações, com menos de $10 \%$ das empresas com tecnologias principais de seus produtos e processos com alto valor agregado, e com menos de $5 \%$ conseguindo efetuar alterações nas tecnologias complementares.

Com relação à gestão ambiental, constata-se limitações em treinamento e conscientização ambiental para os funcionários das empresas. A mediana de $5 \%$ de resíduos de matéria-prima no processo já é preocupante, com somente $51,8 \%$ das empresas praticando reciclagem, além do potencial de resíduos na origem dessa matéria-prima, indicado por $77,7 \%$ das empresas.

Em questionamento administrado, para adoção de novas tecnologias, envolvendo vários fatores, somente 7\% das empresas indicaram o meio ambiente em primeiro lugar.

Para o destino dos resíduos sólidos, somente $50 \%$ das empresas indicaram reciclagem ou comercialização, com as outras 50\% direcionando para descartes sem valor econômico agregado. Quanto a resíduos líquidos, 32\% das empresas indicaram tratamento, e $35 \%$ descartando diretamente em esgoto ou rios. Para resíduos gasosos, $40 \%$ das empresas descartam diretamente na atmosfera, e $48 \%$ efetuam filtragem ou tratamento.

Em questionamento não administrado constatou-se que $53 \%$ das empresas utilizam alguma tecnologia ou procedimentos para redução de resíduos, em sua maior parte após sua geração, com $41 \%$ das empresas praticando alguma reciclagem. Ao redor de $78 \%$ das empresas indicaram que existe potencial de redução de resíduos com intervenção nas tecnologias de produto e processo, procedimento este dependente da capabilidade tecnológica existente nas organizações, como se constatou anteriormente.

As manutenções preventiva e corretiva no processo de produção das empresas são fatores relevantes, tanto para a eficiência do processo industrial como para o meio ambiente, com $77 \%$ das empresas indicando sua prática. Com relação ao uso do produto, $78 \%$ das empresas indicaram não ocorrer emissão de poluentes, e ao redor de $83 \%$ delas não dispõem de maiores informações sobre o que ocorre com o produto após sua vida útil.

Com relação à norma ISO 14000 constata-se que somente $4,5 \%$ delas têm a certificação.

Em questionamento não administrado constata-se que as principais dificuldades das empresas em gestão ambiental se concentram nas tecnologias de processamento de resíduos, nos custos operacionais e de manu- tenção dos sistemas de reaproveitamento, reciclagem ou tratamento, vindo a seguir a legislação, a localização da planta, a pouca cultura ambiental e treinamento.

Resumindo, para a área de meio ambiente, podemos dizer que os dados disponíveis analisados indicaram limitações em $50 \%$ das empresas em vários aspectos do campo da gestão ambiental, entre eles o gerenciamento, as tecnologias, os procedimentos, o treinamento, a conscientização socioambiental, a certificação e a legislação ambiental.

\section{existe correlação positiva entre os níveis de capabilidade tecnológica e os níveis de capabilidade ambiental.}

Concluindo, podemos agora destacar os aspectos mais importantes do relacionamento entre a gestão da tecnologia e a gestão ambiental nas empresas. Uma análise pareada dos questionários de gestão da tecnologia e gestão do meio ambiente, para cada empresa, indicou uma correlação entre a capabilidade tecnológica da empresa e ações no campo da gestão ambiental, havendo limitações nesses dois campos para a maioria das empresas. Pode-se dizer que as maiores dificuldades em gestão ambiental estão nas empresas de menor nível de capabilidade tecnológica, as quais não têm capacidade e habilidade de interferir nas microtecnologias de produtos e de processos, tanto para as tecnologias principais como para as tecnologias complementares.

Quando uma empresa tem capabilidade tecnológica ela consegue interferir nas microtecnologias, visando redução de resíduos, redução do consumo de energia etc., dentro dos conceitos de produção limpa (clean production) e de produção mais limpa (cleaner production). Nesse contexto, existe uma ampliação das relações das dimensões meio ambiente e conservação de energia dentro da matriz de relacionamentos das atividades nas organizações, ou seja, incorporação de novas abordagens no planejamento e na organização.

Podemos então concluir que para a maioria das empresas pesquisadas existe correlação positiva entre os níveis de capabilidade tecnológica e os níveis de capabilidade ambiental, com incorporação da dimensão meio ambiente dentro das atividades das organizações. 


\title{
Artigo recebido em 22/09/2004 Aprovado para publicação em 20/05/2005
}

\section{- Referências Bibliográficas}

ALLEN, T.F.H.; GIAMPIETRO M.; LITTLE A.M. Distinguishing ecological engineering from environmental engineering. Ecological Engineering, v. 20, p. 389407, USA, 2003.

BRYMAN, A. Research methods and organization studies. Londres: Unwin Hyman, UK, 1989.

CAMPBELL, J.P. Editorial: some remarks from the outgoing editor. In: CUMMINGS, L.L.; FROST, P.J. Publishing in the organizational sciences, v. 21, p. 321-33, USA, 1985.

DODGSON. M. The Management of Technological Innovation: An International and Strategic Approach. New York: Oxford University Press, 2000, $248 \mathrm{p}$

DONAIRE, D. Gestão Ambiental na Empresa. São Paulo: Editora Atlas, 1995.

FURTADO, J.S. Auditorias, sustentabilidade, ISO 14000 e producão limpa: limites e mal entendidos, 1998. Disponível em www.vanzolini.org.br/ areas/ desenvolvimento/producaolimpa.

FURTADO, J.S. e FURTADO, M.C. Produção Limpa, in CONTADOR, J.C. (Coord.) Gestão de Operações. São Paulo: Fundação Vanzolini \& Editora Edgard Blucher Ltda. p. 317-329, 1997.

FURTADO, J.S.; SILVA, E.R.F.; MARGARITO, A.C. Estratégias de gestão ambiental e os negócios da empresa. Programa de Produção Limpa, Departamento de Engenharia de Produção e Fundação Vanzolini, Escola Politécnica, USP, S.Paulo, 2001. Disponível em www.vanzolini.org.br/areas/ desenvolvimento/producaolimpa.
HAYES, B.E. Measuring customer satisfaction: development and use of questionaires. Wisconsin: ASQC Quality Press, 1992. 165p. USA.

HILLEBRAND B.; BIEMANS W. G. Links between internal and external cooperation in product development: an exploratory study. Journal od Product Innovation Management, v. 2, p.110-122, USA, 2004.

JACKSON, T. Clean Production Strategies. USA: Lewis Publishers, 1993.

KARLSSON, M.; TRYGG, L.; ELFSTRO B.O. Measuring R\&D productivity: complementing the picture by focusing on research activities. Technovation, v. 24, p. 179-186, USA, 2004

MERLI, G. A evolução estratégica entre clientes e fornecedores. In: Comakership: a nova estratégia para o suprimento (Tradução de Gregório Bouer). Rio de Janeiro: Qualitymark Ed., p. 1-36, 1994.

MICHAEL, A.; HITT, M.A.; IRELAND, R. D.; LEE, $\mathrm{H}$. Technological learning, knowledge management, firm growth and performance: an introductory essay. Journal of Engineering and Technology Management, 17, p. 231246, USA, 2000.

MITSCH W.J.; JØRGENSEN S.E. Ecological engineering: A field whose time has come. Ecological Engineering, v. 20 , p. $363-377$, USA, 2003
MOHRMAN, S.A. FINEGOLD, D MOHRMAN, A.M.Jr. An empirica model of the organization knowledge system in new product development firms. Journal of Engineering Technology Management, v. 20, p. 7-38, USA, 2003.

PETERSEN, K.J.; HANDFIELD, R.B.; RAGATZ, G.L. A Model of Supplier Integration into New Product Development. Journal of Product Innovation Management, v. 20, p. 284299, USA, 2003.

PHILLIPS, F.; PUGH, D.S. How to ge a PhD. Open University Press, Milton Keynes, USA, 1989.

SIEGEL, S. Estatística não-paramétrica (para as ciências do comportamento). São Paulo: Ed. McGraw-Hill, 1975.

SILVA, J.C.T.; PLONSKI, G.A. Inovação Tecnológica : Desafio Organizacional. Revista Produção, ABEPRO, v. 6, n. 2 , p. 183-93, 1996 (ISSN 0103-6513).

SILVA, J.C.T. Modelo interativo empresa-universidade no desenvolvimento de produtos, 1999a. 163 p. Tese (Doutorado) - Departamento de Engenharia de Produção, Escola Politéc nica, Universidade de São Paulo, São Paulo, 1999.

SILVA, J.C.T.; PLONSKI,G.A. Gestão da tecnologia: desafios para pequenas médias empresas, Revista Produção, Associação Brasileira de Engenharia de Produção - ABEPRO, Rio de Janeiro, v. 9 , n. 1 , p. 23-30. (ISSN 01036513)
SILVA, J.C.T. Dimensões de competitividade para a empresa brasileira: informação e conhecimento, qualidade, tecnologia e meio ambiente. Revista Transinformação-PUC, Campinas, v. 13 n. 2, p. 81-92, 2001. (ISSN 0103 - 3786)

SILVA, J.C.T. Tecnologia : Conceitos e Dimensões. In: XXII ENCONTRO NACIONAL DE ENGENHARIA DE PRODUCÃO - ENEGEP E VII CONGRESSO INTERNACIONAL DE ENGENHARIA INDUSTRIAL. Pontifícia Universidade Católica do Paraná-PUC-PR, Curitiba PR, Anais em CD ROM, 2002a.

SILVA, J.C.T. Gestão da tecnologia em empresas de manufatura. In: Tópicos Emergentes em Engenharia de Produção, v. 1/ José Paulo Alves Fusco (Org.) São Paulo: Editora Arte \& Ciência, cap. 13, p. 285-324. 2002b. (ISBN 85-7473-091-2)

SILVA, J.C.T. Tecnologia : novas abordagens, conceitos, dimensões e gestão. Revista Produção-ABEPRO, Porto Alegre, v. 13, n. 1, p. 50-63. 2003 (ISSN 0103-6513)

SWAN, K.S. ; ALLRED, B.B. A product and process model of the technologysourcing decision. Journal of Product Innovation Management, v. 20, p. 485 496, 2003.

WHITE, P.; FRANKE, M.; HINDLE, P. Integrated solid waste management: a lifecycle inventory. London Chapman\&Hall, First Edition, 1996.

WOLSTENHOLME, E.F. The use of system dynamics as a tool for intermediate level technology evaluation:three case studies. Journal of Engineering Technology Management, v. 20, p. 193-204, UK, 2003.

\section{- Sobre o autor}

José Carlos Teixeira da Silva, Dr. Eng. Produção/Poli - USP

Prof. Dr. Depto. Eng. Produção - UNESP - Bauru - SP

Endereço: Av. Luiz Edmundo C. Coube s/n - CEP 17033-360 - Bauru-SP - Fone: (14) 3103-6122

E-mail: jcteixe@feb.unesp.br

\author{
Marcos Schaaf Teixeira da Silva, Saneamento e Controle Ambiental \\ UNICAMP - Limeira-SP \\ Endereço: Praça Japuba, 35, apto. 44B - CEP 05453-060 - São Paulo - SP - Fone (11) 3021-3590 \\ E-mail: msts900@uol.com.br
}

Jair Wagner de Souza Manfrinato, Dr. Agronomia - UNESP

Prof. Dr. Depto. Eng. Produção - UNESP - Bauru-SP

Av. Luiz Edmundo C. Coube s/n - CEP 17033-360 - Bauru - SP - Fone (14) 3103-6122

E-mail: jwsouza@feb.unesp.br 